OPEN ACCESS

Edited by:

Virginia Penhune,

Concordia University, Canada

Reviewed by:

Nai Ding,

Zhejiang University, China

Peter Schneider,

Heidelberg University, Germany

Peter Keller,

Western Sydney University, Australia

*Correspondence: Jan Stupacher jan.stupacher@uni-graz.at

Specialty section:

This article was submitted to Auditory Cognitive Neuroscience,

a section of the journal

Frontiers in Neuroscience

Received: 21 November 2016

Accepted: 28 March 2017

Published: 12 April 2017

Citation:

Stupacher J, Wood G and Witte M

(2017) Neural Entrainment to Polyrhythms: A Comparison of Musicians and Non-musicians.

Front. Neurosci. 11:208

doi: 10.3389/fnins.2017.00208

\section{Neural Entrainment to Polyrhythms: A Comparison of Musicians and Non-musicians}

\author{
Jan Stupacher ${ }^{1 *}$, Guilherme Wood ${ }^{1,2}$ and Matthias Witte ${ }^{1}$ \\ ${ }^{1}$ Department of Psychology, University of Graz, Graz, Austria, ${ }^{2}$ BioTechMed-Graz, Graz, Austria
}

Music can be thought of as a dynamic path over time. In most cases, the rhythmic structure of this path, such as specific sequences of strong and weak beats or recurring patterns, allows us to predict what and particularly when sounds are going to happen. Without this ability we would not be able to entrain body movements to music, like we do when we dance. By combining EEG and behavioral measures, the current study provides evidence illustrating the importance of ongoing neural oscillations at beat-related frequencies -i.e., neural entrainment-for tracking and predicting musical rhythms. Participants (13 musicians and 13 non-musicians) listened to drum rhythms that switched from a quadruple rhythm to a 3-over-4 polyrhythm. After a silent period of $\sim 2-3 \mathrm{~s}$, participants had to decide whether a target stimulus was presented on time with the triple beat of the polyrhythm, too early, or too late. Results showed that neural oscillations reflected the rhythmic structure of both the simple quadruple rhythm and the more complex polyrhythm with no differences between musicians and non-musicians. During silent periods, the observation of time-frequency plots and more commonly used frequency spectra analyses suggest that beat-related neural oscillations were more pronounced in musicians compared to non-musicians. Neural oscillations during silent periods are not driven by an external input and therefore are thought to reflect top-down controlled endogenous neural entrainment. The functional relevance of endogenous neural entrainment was demonstrated by a positive correlation between the amplitude of task-relevant neural oscillations during silent periods and the number of correctly identified target stimuli. In sum, our findings add to the evidence supporting the neural resonance theory of pulse and meter. Furthermore, they indicate that beat-related topdown controlled neural oscillations can exist without external stimulation and suggest that those endogenous oscillations are strengthened by musical expertise. Finally, this study shows that the analysis of neural oscillations can be a useful tool to assess how we perceive and process complex auditory stimuli such as polyrhythms.

Keywords: music cognition, rhythm perception, entrainment, temporal prediction, neural oscillations, steady-state evoked potentials, EEG, musical training 


\section{INTRODUCTION}

Temporal aspects of music-the organization of sounds into patterns and the unfolding of those patterns over time-allow us to predict what and when sounds are likely to occur next. It is supposed that such expectations and predictions are crucial for the experience of pleasure during music listening (Salimpoor et al., 2015). Thus, the question of how we track the temporal structure of music is key for understanding why we love music.

On a basic level, musical rhythms can be defined as acoustic sequences with patterns of duration and accentuation; they represent the structure of music (London, 2004; Large et al., 2015). We can tap our feet or bob our heads in time with music because we are usually able to perceive a regular beat or pulse within a rhythm. If we perceive strong and weak beats, detect regularly recurring events, and use these events to group a fixed number of beats in cycles, we can be said to have found the meter of a musical piece (London, 2004). Broadly speaking, a quadruple meter encourages us to tap our feet four times (beat-level) in each cycle (bar-level), whereas a triple meter encourages us to tap three times in each cycle.

Polyrhythms consist of at least two different beat-levels ( $\mathrm{N}$ and $\mathrm{M}$ ) within one bar-level, whereby $\mathrm{N}$ and $\mathrm{M}$ have to be relatively prime (i.e., they have no common roots; Large and Kolen, 1994). Polyrhythms, such as $3: 2,4: 3,5: 4$, or $7: 5$, create rhythmic tension and are used in different genres including, but not limited to jazz (Pressing, 2002), rock, metal (Pieslak, 2007; Osborn, 2010), African drumming (Locke, 1982), and twentieth century Western art music (Poudrier and Repp, 2013). Described from a perspective of embodiment, polyrhythms can be seen as contrasting but coordinated body movements (Iyer, 2002). For example, let us imagine a 3:2 polyrhythm. A dancer listening to this polyrhythm might stamp his or her feet three times each cycle, aligned with the triple beat, while in the same amount of time moving his or her upper body once to the left and once to the right in time with the duple beat.

Various bimanual tapping studies predominantly conclude that contrasting pulse trains in simple polyrhythms are not processed by parallel timekeepers, but integrated into one shared rhythmic framework (e.g., Klapp, 1979; Deutsch, 1983; Klapp et al., 1985, 1998; Jagacinski et al., 1988; Summers and Kennedy, 1992; Summers et al., 1993; Peper et al., 1995; Krampe et al., 2000; Kurtz and Lee, 2003). However, at least in professional musicians, bimanual tapping of faster polyrhythms might be controlled by independent timekeepers (Krampe et al., 2000). Even without overt movements, integrated processing of contrasting patterns can be beneficial when tracking polyrhythms (e.g., Jones et al., 1995; Klein and Jones, 1996). Jones et al. (1995) examined attentional strategies of musicians and non-musicians when trying to detect timing changes of target tones in 3:2 polyrhythms. In a series of experiments that encouraged either integrative or selective attending, the authors found that although musicians as compared to non-musicians were more accurate in detecting timing changes, they were not better at adjusting their attentional strategy (i.e., choosing integrated vs. selective attending).

Whereas, most of the aforementioned studies used simple polyrhythms consisting of two contrasting isochronous pulse trains, Poudrier and Repp (2013) examined whether classically trained musicians use divided or selective attention when keeping track of polyrhythms of different complexities in a perceptual probing paradigm. In simple polyrhythms the two contrasting parts (2/4 and 6/8 meter) could be tracked simultaneously. However, more complex polyrhythms limited the musicians' ability to divide their attention. Keller and Burnham (2005) found similar results in a dual-task paradigm that examined the recognition and reproduction of matched-metrical and mismatched-metrical rhythmic patterns. In a recent study, Wöllner and Halpern (2016) asked expert and novice conductors and pianists to detect pitch and timing deviations of target tones in selective- and divided-attention tasks (focus on one of two melodic streams, and focus on both streams, respectively). They found that in both tasks experts detected more targets than students. Furthermore, conductors-specialists in monitoring multiple parts of a musical piece simultaneously-detected more targets than pianists in the divided-attention task.

Training-related differences were also shown in sensorimotor synchronization studies. Finger tapping studies show that musical training can sharpen rhythm perception and production (e.g., Chen et al., 2008; Cameron and Grahn, 2014; Matthews et al., 2016). Another tapping study by Drake et al. (2000b) suggests that musicians as compared to non-musicians have a better apprehension of metric structure and can process a wider range of hierarchical levels. These behavioral results are supported by EEG studies examining event-related potentials (ERPs) elicited by target tones within musical rhythms. In isochronous sequences of unaccented tones that typically induce binary subjective accenting ("tick"-“tock"-“tick"-“tock"...), ERPs differed more strongly between deviants that fell on subjectively strong and subjectively weak beats for musicians as compared to non-musicians (Brochard et al., 2003). Another study found that, in musicians but not in non-musicians, mismatch negativities (MMN: an ERP difference measure that is increased by unexpected stimuli) were elicited by violations of numerical regularity in tone sequences (van Zuijen et al., 2005). Additionally, the difference between MMNs elicited by meter-congruent and meter-incongruent target tones was larger in musicians as compared to non-musicians (Geiser et al., 2010).

The enhanced ability of musicians in the processing of hierarchical temporal structures might relate to an increased involvement of the working memory, as reflected by an enhanced recruitment of the dorsolateral prefrontal cortex (Chen et al., 2008). Musicians' advantages in rhythm perception and performance can be linked to the tight coupling between sensory and motor areas of the brain that develops through musical training and experience (Haueisen and Knösche, 2001; Bangert and Altenmüller, 2003; Bangert et al., 2006; D'Ausilio et al., 2006; Grahn and Rowe, 2009; Stupacher et al., 2013). Although, previous research has shown differences between musicians and non-musicians in sensorimotor synchronization, perceptual organization of rhythm, and neural processing, it remains an open question whether rhythm-related neural oscillations are modulated by musical expertise and in which ways (Nozaradan, 2014). 
Neural oscillations are based on synchronized fluctuations between high and low excitability states in groups of neurons (Singer, 1999; Fries, 2005), a function that is, among others, important for attention and prediction (Buzsáki and Draguhn, 2004; Schroeder and Lakatos, 2009; Arnal and Giraud, 2012; Frey et al., 2015). In music, meter describes the percept of a regular temporal structure with alternating strong and weak events. Resonance theories link pulse and meter perception with neural oscillations (Large, 2008). They assume that when neural oscillations entrain to a stimulus with at least some temporal regularity, such as most music, high neural excitability states and the underlying pulse of the musical rhythm become aligned (Large and Kolen, 1994; Large and Jones, 1999; Large, 2008; Schroeder and Lakatos, 2009). When measured with EEG, such entrained oscillations are called steady-state evoked potentials (SSEP) and are reflected in amplitude peaks in the frequency spectra of ongoing signals. In a series of studies Nozaradan and colleagues showed that beat-related SSEPs are influenced by the imagination of accents within unaccented isochronous pulse trains (duple vs. triple meter imagery; Nozaradan et al., 2011), are present with rhythmic patterns whose envelope spectra do not necessarily have maximum peak amplitudes at the beat frequency (Nozaradan et al., 2012a), and relate to sensorimotor coupling (Nozaradan et al., 2015). Whereas, Nozaradan and colleagues used abstract and relatively simple auditory stimuli, Tierney and Kraus (2015) showed that neural entrainment also plays a key role in tracking the rhythm of real music.

In a previous experiment we used pop/rock drum rhythms and isochronous pulse trains to show that, during listening, stimuli with more complex rhythmic hierarchies, as compared to isochronous stimuli, elicited more pronounced SSEPs at the beat's second harmonic frequency (Stupacher et al., 2016). In the same experiment, auditory stimuli were interrupted by silent breaks (2-6s), allowing us to examine whether neural oscillations persist without external stimulation as well as to connect ongoing neural oscillations (SSEPs) and transient neural responses (ERPs). Similar to the SSEP results, the N1 ERP component indicated that listening to more complex rhythms increased neural entrainment. Although, we were not able to directly show neural oscillations in the frequency domain during silent breaks, N1 results suggested that beat-related oscillations persist throughout the breaks, but become blurred and/or decrease in their amplitude with increasing time. This is an important finding, as it suggests that beat-related neural oscillations are not merely a reflection of the auditory stimulus (bottom-up processing), but rather involve top-down endogenous timing processes.

The silent break design indirectly instructed the participants to imagine that the rhythm continued during silence. Gordon $(1985,1999)$ coined the term audiation, which describes the hearing of music in the mind. Audiation involves the interpretation and understanding of what was just heard, recalled, composed or performed. Several neuropsychological studies indicate that the auditory cortex can be active without the actual presence of sound and suggest that musical imagery is related to this activity (Zatorre and Halpern, 2005). Audiation, or more generally musical imagery, is an important part of music education (e.g., Gordon, 1999). A recent study showed that musical training and higher musical engagement were associated with better performance in a musical tempo imagery task (Jakubowski et al., 2016).

In the current experiment, we decided to adapt the silent break design of Stupacher et al. (2016). Musicians and non-musicians listened to auditory stimuli that started with an isorhythmic quadruple drum rhythm and turned into a 3-over-4 (4:3) polyrhythm. After the polyrhythm, we included a silent period of $\sim 2$ to $3 \mathrm{~s}$ after which a target stimulus was presented. Participants had to decide whether this target stimulus fell on the timing grid of the triple-beat part of the 4:3 polyrhythm or was presented 220 $\mathrm{ms}$ too early or $220 \mathrm{~ms}$ too late. This design allowed us to address various open questions: How do neural oscillations evolve during listening to stimuli with changing metrical hierarchies? Do neural oscillations persist without an acoustic input when the task demands to imagine that the beat goes on? And does musical expertise modulate neural entrainment?

\section{METHODS}

\section{Participants}

Twenty-six adults ( 11 female; mean age $=26.8$ years, $S D=7.07$ ) participated in the experiment. One additional participant was excluded due to an unacceptable amount of noise in the EEG recording. Thirteen participants (6 female), hereafter referred to as musicians, had played their primary instrument (including drums/percussion, piano, guitar, bass, and violin/viola) for $M=$ 15.5 years $(S D=3.71)$. The average amount of formal training on their primary instruments was 11.8 years $(S D=5.13)$. The starting age of the musicians ranged from 5 to 12 years $(M=7.9$ years, $S D=2.43)$. Seven musicians played a second instrument $(M=8.8$ years, $S D=5.00)$, and two musicians played a third instrument (4 and 9.5 years). Ten musicians played in ensembles for $M=7.2$ years $(S D=4.44)$. The remaining 13 participants, hereafter referred to as non-musicians, had no musical training. Participants gave written informed consent in accordance with the Declaration of Helsinki and were paid for their participation. The study was approved by the ethics committee of the University of Graz.

\section{Auditory Stimuli}

Auditory stimuli were programmed with the software Ableton Live (version 8; Ableton AG, Berlin, Germany) and consisted of four different basic pop/rock drum rhythms played by bass drum, snare drum and hi-hat (Figure 1A and Supplementary Material). Variations of the drum rhythms were subtle and only applied to the bass drum track. The hi-hat and snare drum tracks were identical in all four drum rhythms. The rhythms were created in quadruple meter $(1-2-3-4-/ 1-2 \ldots)$ at a tempo of 120 beats per minute (BPM) and lasted four bars (i.e., four cycles of four beats, $8 \mathrm{~s}$ in total). The tempo was chosen because previous research shows that $120 \mathrm{BPM}(2 \mathrm{~Hz})$ is an intuitive and comfortable rate for sensorimotor synchronization (van Noorden and Moelants, 1999; Drake et al., 2000a; MacDougall and Moore, 2005; Repp, 2005). After two bars (4 s) a woodblock sound with 

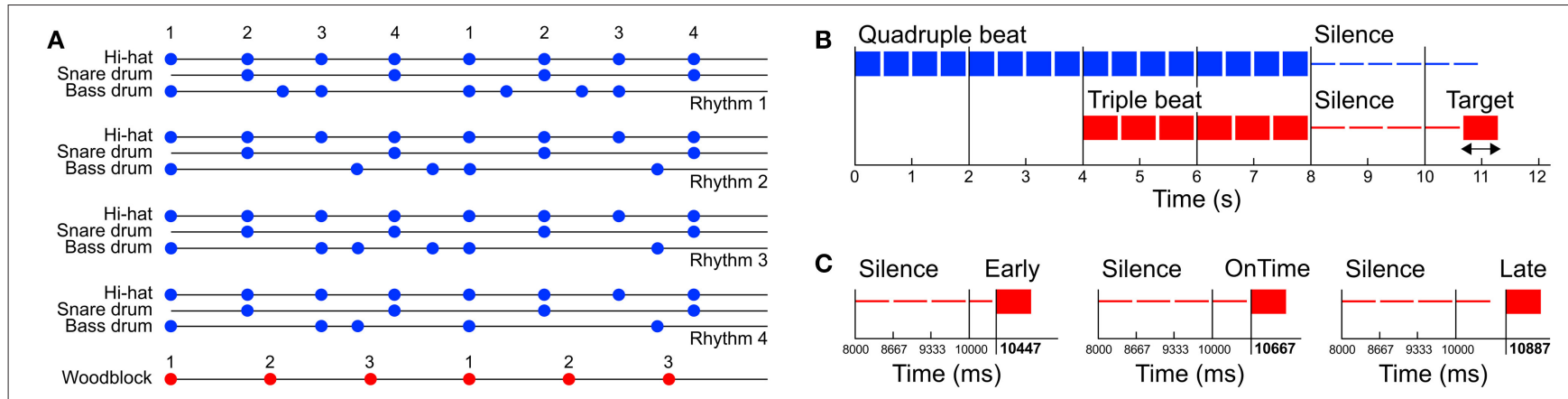

FIGURE 1 | (A) Structure of the four quadruple rhythms consisting of hi-hat, snare drum, and bass drum (blue dots, Rhythms 1-4) and the triple beat consisting of a woodblock sound (red dots). Numbers represent the beat count. (B) Structure of one trial. Before the stimuli started two metronome clicks were presented at the same rate as the quadruple beat $(-1,000$ and $-500 \mathrm{~ms})$. The trials were composed of one of the four quadruple rhythms (0-4 s), followed by a $4: 3$ polyrhythm including the triple-beat woodblock (4-8s). After a subsequent silent period with varying duration a target stimulus was presented. (C) The target stimulus was either presented directly on the timing grid of the cycles second triple beat (on time, mid panel), 220 ms too early (left panel), or 220 ms too late (right panel). Note that the second triple beat does not coincide with a quadruple beat.

three evenly distributed tone onsets per bar $(1-2-3-/ 1-$ 2...) was added to the isorhythmic drum rhythms, resulting in a simple 4:3 polyrhythm (Figure 1B). This isochronous triple woodblock beat was the same for each of the four quadruple drum rhythms. The volume and timbre of the woodblock sound was optimized to make it clearly audible and distinguishable, as previous research suggests that larger pitch separations between two contrasting parts of a polyrhythm make it easier to focus on a single part and make an integrated representation of the two parts less likely (Klapp et al., 1985; Moelants and van Noorden, 2005; Fidali et al., 2013). Figure 2A shows the frequency spectra of the audio waveforms of the different instruments.

Quadruple drum rhythms were quantized on an eighth note level (250 ms grid), whereas the triple woodblocks were quantized on a $666.67 \mathrm{~ms}$ grid (exactly 3 onsets per bar). The two bars of quadruple rhythm and the subsequent two bars of 4:3 polyrhythm were followed by a silent period of four triple notes $(1-2-3-/ 1-)$. After this silent period a target stimulus was presented with the same woodblock sound as in the $4: 3$ polyrhythm. The target stimulus was either perfectly in time with the second triple beat, $220 \mathrm{~ms}$ too early, or $220 \mathrm{~ms}$ too late (Figure 1C). We chose to present the target stimulus on the second beat of the triple meter because the first triple beat would have matched with the first quadruple beat (Figure 1) and the task of the participants was to focus on the triple beat (see Design and Procedure Section below).

Figure 2B shows the frequency spectra of the sound envelopes of the four quadruple drum rhythms (first $4 \mathrm{~s}$ of each trial; top panel) and the corresponding frequency spectra of the $4: 3$ polyrhythms (4-8 s of each trial; bottom panel).

To make it easier for the participants to "get into the beat," and to allow some time for beat-related neural oscillations to evolve, two clicks were presented at the quadruple beat rate before the rhythms started $(-1,000$ and -500 ms relative to the first onset of the rhythms).

\section{Design and Procedure}

Participants sat in a cushioned chair with an attached table on which they could rest their arms. They were instructed to sit relaxed and to avoid general movements and movements in time with the musical rhythms. To monitor body movements, electromyography (EMG) signals were recorded from the neck (splenius capitis), both arms (extensor digitorum communis), and both legs (musculus tibialis anterior) using $\mathrm{Ag} / \mathrm{AgCl}$ electrodes and a ground electrode on the clavicle.

Auditory stimuli were presented with the software Presentation (version 17; Neurobehavioral Systems, Berkeley, CA), an ART HeadAmp 4 headphone amplifier (Art Pro Audio, Niagara Falls, NY), and Aircom A5 Airtube in-ear headphones (Aircom Audio Inc., Brea, CA). Twelve different trials resulted from the combination of the four different rhythms and the three different positions of the target stimulus ( $220 \mathrm{~ms}$ too early, on time, or $220 \mathrm{~ms}$ too late). Participants were presented 10 blocks with all 12 trials, resulting in 120 trials in total.

The task was explained in an instruction video that showed how the auditory stimuli were structured and included an example stimulus. Participants were instructed to focus on the triple beat of the $4: 3$ polyrhythm, to try to imagine how this beat continues, and to decide whether the target stimulus after the silent period was exactly on time with the triple beat, too early, or too late. The answer was given on a computer keyboard with the left arrow key for targets that were too early, the up arrow key for targets on time, and the right arrow key for targets that were too late. During the presentation of the stimuli a fixation cross was displayed on a computer monitor $1.5 \mathrm{~m}$ in front of the participants. One second after the target stimulus was presented, participants were asked to make their decision. As soon as they pressed one of the arrow keys the next trial started with a delay of $2 \mathrm{~s}$. After each block of 12 trials, participants had the chance to take a break and to continue the next block by pressing the space bar. To ensure that participants understood the task, five practice trials were observed by the experimenter. 

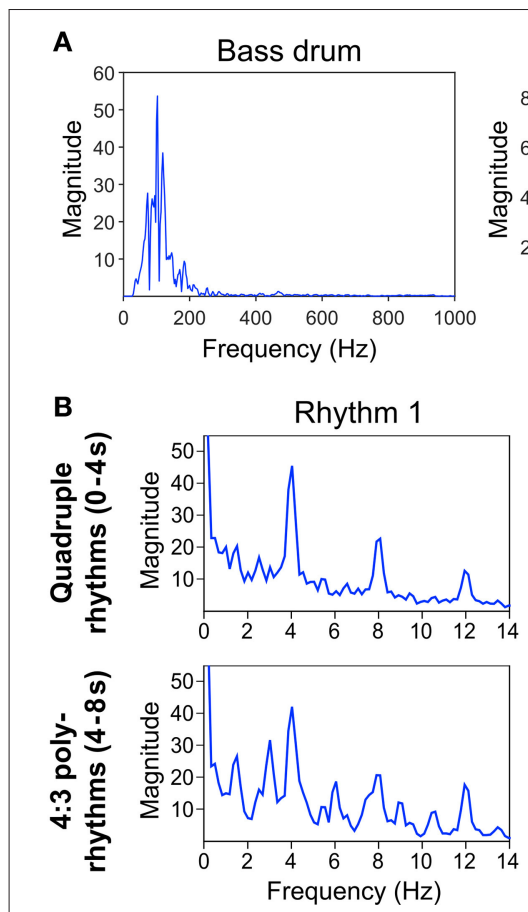

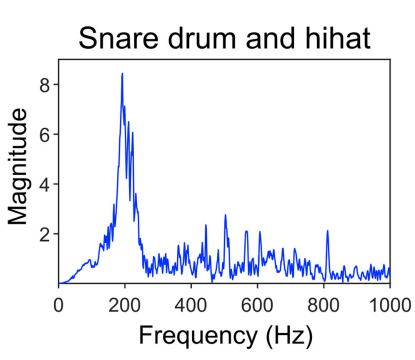

Rhythm 2
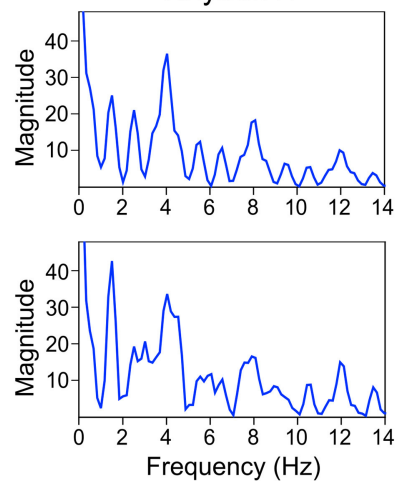

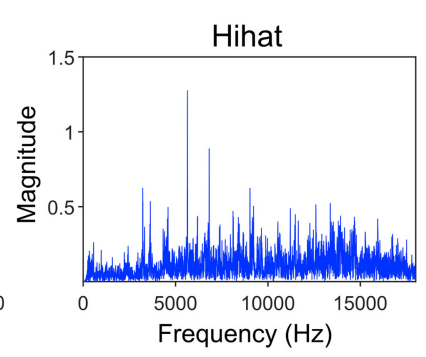

Rhythm 3
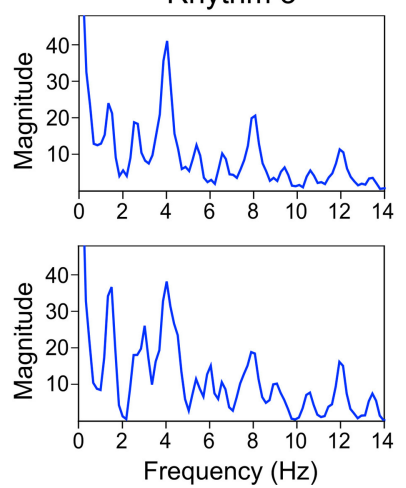

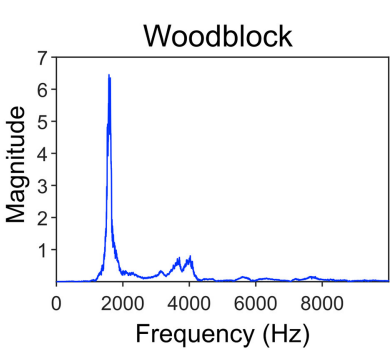

Rhythm 4
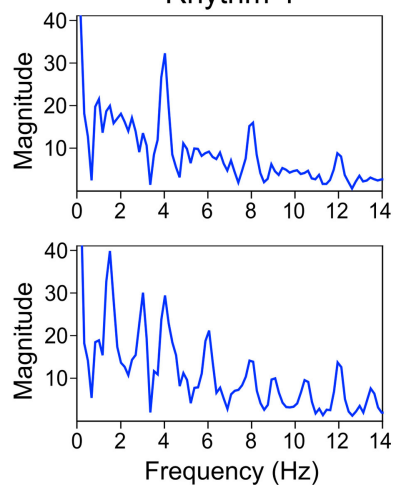

FIGURE 2 | (A) Frequency spectra of the different instruments' audio waveforms. (B) Frequency spectra of the sound envelopes of quadruple rhythm parts (0-4 s, top panel) and corresponding 4:3 polyrhythm parts (4-8s, bottom panel) of the four different rhythms depicted in Figure 1A. Envelopes and spectra were computed with mirenvelope and mirspectrum of the MIR toolbox 1.6 for Matlab (Lartillot and Toiviainen, 2007).

At the beginning and at the end of the experiment, participants additionally listened to a 2 -min recording of the woodblock sound with a $666.67 \mathrm{~ms} / 1.5 \mathrm{~Hz}$ inter-onset-interval (i.e., the same stimulus that was used to create the $4: 3$ polyrhythms in combination with the quadruple drum rhythms). Hereafter we refer to this metronome as triple metronome.

\section{EEG Recording}

Fifteen $\mathrm{Ag} / \mathrm{AgCl}$ electrodes were placed on the scalp according to the international 10-20 system to record the electroencephalogram (EEG). The AFz electrode was used as ground and two additional reference electrodes were placed on the left and right mastoids. To control for eye movements, two electrodes were placed on the outer canthi of the eyes, and one electrode was placed above the nasion. Impedances of electrodes were kept under $10 \mathrm{k} \Omega$. The continuous EEG signal was amplified, digitized with a resolution of $1,000 \mathrm{~Hz}$ and pre-filtered with a notch filter at $50 \mathrm{~Hz}$ using a BrainAmp Standard amplifier (Brain Products GmbH, Gilching, Germany).

\section{Data Processing}

EEG signals were preprocessed and analyzed with the software Brain Vision Analyzer (version 2.1; Brain Products GmbH, Gilching, Germany). The signals were referenced to linked mastoids, high-pass filtered $(0.2 \mathrm{~Hz}, 24 \mathrm{~dB}$ /octave), and corrected for eye movements based on Gratton et al. (1983).

\section{Steady-State Evoked Potentials}

EEG signals of each trial were segmented in three different parts that corresponded to the different parts in the auditory stimuli: quadruple rhythm (4 s), 4:3 polyrhythm (4s), and silent break (2.33 s; Figure 1B). The EEG signals during 2min listening to the triple metronome before and after the experiment were segmented in $4 \mathrm{~s}$ segments. The first of those segments was removed to exclude ERPs related to the onset of the stimuli (Nozaradan et al., 2011). Segments with voltage steps above $120 \mu \mathrm{V} / \mathrm{ms}$, or over $200 \mu \mathrm{V}$ in a $200 \mathrm{~ms}$ time window were rejected (3.49\%). Overall numbers of averaged segments for the different parts of the auditory stimuli were 111.8 for quadruple drum rhythms, 116.3 for 4:3 polyrhythms, 117.4 for silent periods (maximum $N=120$, respectively), and 57.9 for the triple metronome (maximum $N=58$ ). First, EEG segments were averaged across trials for each participant in the time domain. Signals of the five fronto-central electrodes (Fz, FC1, FCz, FC2, Cz) were then averaged, because SSEPs are predominant in this area (Nozaradan et al., 2011, 2012a,b; Tierney and Kraus, 2015; Stupacher et al., 2016). The averaged signals were finally transformed from the time domain into the frequency domain via discrete fast Fourier transformation (FFT) with a frequency resolution of $0.1 \mathrm{~Hz}$ and $10 \%$ overlapping Hanning windows. Amplitudes of beat-related frequencies $\left(f_{n}\right)$ in the frequency spectra were normalized with the mean amplitude of four surrounding frequencies $\left(f_{n}-0.3 \mathrm{~Hz}, f_{n}-0.2 \mathrm{~Hz}, f_{n}+0.2\right.$ $\mathrm{Hz}, \mathrm{f}_{\mathrm{n}}+0.3 \mathrm{~Hz}$; Figure 3). To assess whether SSEPs were elicited, 


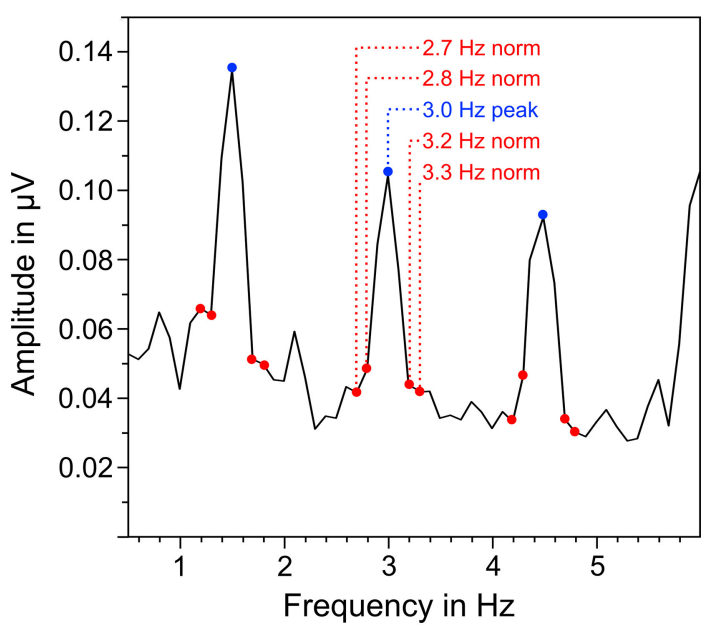

FIGURE 3 | Exemplary illustration of the normalization of neural oscillations at beat-related frequencies. The mean amplitude of surrounding frequencies (marked in red) was subtracted from the amplitude at the corresponding beat-related frequency (marked in blue).

the resulting normalized amplitudes were compared against zero in one-sample $t$-tests.

The SSEP analysis was focused on the first $\left(f_{1}\right)$ and second $\left(f_{2}\right)$ harmonic frequency corresponding to quarter and eighth notes (Stupacher et al., 2016). Mean of 2 and $4 \mathrm{~Hz}$ normalized spectral peaks were computed to evaluate SSEPs elicited by quadruple rhythms and 4:3 polyrhythms, and ongoing neural oscillations during silent periods. Accordingly, 1.5 and $3 \mathrm{~Hz}$ normalized spectral peaks were averaged to evaluate SSEPs elicited by $4: 3$ polyrhythms and the triple metronome, and ongoing neural oscillations during silent periods.

Beat-related neural oscillations during silent periods were additionally analyzed separately for correct and incorrect responses to the target stimuli. The average number of segments used to compute the frequency spectra was 52.0 for correct responses and 65.4 for incorrect responses. The remaining processing steps were identical to those mentioned above.

\section{Time-Frequency Analysis}

To explore how neural entrainment evolves with auditory stimuli, we additionally computed time-frequency plots based on the full trials. The $10.33 \mathrm{~s}$ segments included the quadruple rhythms (0-4s), the $4: 3$ polyrhythms (4-8s), and the subsequent silent periods without the target stimuli $(8-10.33 \mathrm{~s})$. Trials that included artifacts (voltage steps over $120 \mu \mathrm{V} / \mathrm{ms}$, or over $200 \mu \mathrm{V}$ in a $200 \mathrm{~ms}$ time window) were rejected, resulting in an average of 109.8 of 120 segments per participant. Segments were averaged in the time domain for each participant. The resulting signals of the five fronto-central electrodes were combined. Individual time-frequency plots for each participant were computed with continuous Morlet wavelet transformations (Morlet parameter $c=13$, linear frequency steps from 1 to $8.5 \mathrm{~Hz}$ with a resolution of $0.125 \mathrm{~Hz}$ ). The resulting plots were averaged across participants.

\section{EMG Control}

To ensure that SSEPs were solely based on neural activity and not on beat-related body movements, EMG signals from the neck (splenius capitis), both arms (extensor digitorum communis), and both legs (musculus tibialis anterior) were transformed into the frequency domain and normalized in the same way as the EEG signals. Normalized spectral peaks of all five muscles were averaged. Spectral peaks related to the quadruple beat ( 2 and $4 \mathrm{~Hz})$ and to the triple beat $(1.5$ and $3 \mathrm{~Hz})$ were averaged. $T$-tests against zero on the resulting averaged spectral peaks indicated that there were no beat-related body movements (Table 1).

\section{Event-Related Potentials}

In addition to ongoing neural oscillations, we analyzed transient neural activity evoked by the target stimuli (i.e., ERPs). Trials that included artifacts in EEG or EOG channels (voltage steps over $120 \mu \mathrm{V} / \mathrm{ms}$, or over $120 \mu \mathrm{V}$ in a $200 \mathrm{~ms}$ time window) were rejected. After baseline corrections ( -200 to $0 \mathrm{~ms}$ before stimulus onset) and low-pass filtering $(20 \mathrm{~Hz}, 48 \mathrm{db} /$ octave), ERPs corresponding to correct behavioral responses $(M=52.1$ segments) and incorrect responses $(M=64.7$ segments of a maximum of 120 segments, respectively) were averaged across trials in the three different target time conditions for each participant. The average number of segments per participant and target time was $17.4(S D=8.9)$ for correct responses and 21.6 $(S D=8.7)$ for incorrect responses. One participant was excluded from the analysis due to an insufficient number of artifact-free segments ( $<10$ per target time). In three cases the number of segments per target time was below 4 . Those values were replaced by the mean values of all participants in that condition. Similar to the analysis of SSEPs, amplitudes of fronto-central electrodes (Fz, FC1, FCz, FC2, Cz) were averaged. The ERP analysis was focused on P1, N1, and P2 components that are relevant for rhythm perception. The earlier components, such as P1 and N1, are typically attenuated with increasing predictability (Moberget et al., 2008; Lange, 2009; Bendixen et al., 2012; Sanabria and Correa, 2013; Stupacher et al., 2016), whereas the P2 component may be enhanced with increasing predictability (Sanabria and Correa, 2013). The local positive maximum between 30 and $90 \mathrm{~ms}$ after stimulus onset (P1), the local negative maximum between 50 and $180 \mathrm{~ms}$ after stimulus onset (N1), and the local positive maximum between 150 and $300 \mathrm{~ms}$ after stimulus onset (P2) was extracted for each individual participant. The mean amplitude of a time window of $\pm 5 \mathrm{~ms}$ around these peaks was exported for statistical analyses.

\section{RESULTS}

\section{Behavioral Results}

A repeated measures ANOVA on the percentage of correct answers with the within-subject factor target time (early, on time, and late) and the between-subject factor musical expertise revealed a main effect of target time $\left[F_{(2,48)}=10.28, p<0.001\right.$, $\eta_{p}{ }^{2}=0.30$; Figure 4]. Early targets $(M=63 \%, S D=23)$ were correctly identified more often than on time targets $[M=53 \%$, $\left.S D=12 ; t_{(25)}=1.07, p=0.049\right]$ and late targets $[M=37 \%$, $\left.S D=21 ; t_{(25)}=3.51, p=0.002\right]$. Additionally, on time targets 
were identified correctly more often than late targets $\left[t_{(25)}=3.11\right.$, $p=0.005]$. Musicians $(M=53 \%, S D=6)$ tended to answer correctly more often than non-musicians $[M=48 \%, S D=8$; $\left.F_{(1,24)}=3.42, p=0.077, \eta_{p}^{2}=0.16\right]$. No interaction between target time and musical expertise was found $\left[F_{(2,48)}=2.30\right.$, $p=0.112]$. Individual $t$-tests showed that musicians answered correctly more often than non-musicians for early targets $\left[t_{(24)}\right.$ $=2.30, p=0.030]$, but not for on time or late targets ( $p s>0.27)$.

\section{Steady-State Evoked Potentials}

Figure 5 shows the mean frequency spectra of participants' oscillatory brain activations during the different segments of the auditory stimuli. As expected, quadruple drum rhythms (Figure 5A) elicited clear amplitude peaks at $2 \mathrm{~Hz}\left(\mathrm{f}_{1}\right), 4 \mathrm{~Hz}$ $\left(f_{2}\right)$, and $8 \mathrm{~Hz}\left(f_{4}\right)$, and a smaller peak at $6 \mathrm{~Hz}\left(f_{3}\right)$. The same amplitude peaks $(2,4,6$, and $8 \mathrm{~Hz})$ can be found in the frequency

TABLE 1 | Results of $t$-tests against zero on normalized mean EMG activity recorded from neck, arms, and legs for musicians and non-musicians combined.

\begin{tabular}{lccccc}
\hline & & $\begin{array}{c}\text { Quadruple } \\
\text { rhythms }\end{array}$ & $\begin{array}{c}\mathbf{4 : 3} \\
\text { polyrhythms }\end{array}$ & $\begin{array}{c}\text { Silent } \\
\text { breaks }\end{array}$ & $\begin{array}{c}\text { Triple } \\
\text { metronome }\end{array}$ \\
\hline $\begin{array}{l}\text { 2 and } 4 \mathrm{~Hz} \\
\text { normalized peaks }\end{array}$ & $t_{(25)}$ & 1.29 & 1.18 & -0.87 & -0.99 \\
\hline $\begin{array}{l}1.5 \text { and 3 Hz } \\
\text { normalized peaks }\end{array}$ & $t_{(25)}$ & -1.58 & 1.10 & 0.56 & 0.30 \\
& $p$ & 0.1210 & 0.251 & 0.395 & 0.334 \\
& $p$ & 0.281 & 0.583 & 0.769
\end{tabular}

The non-significant results indicate that participants did not move their body in time with the stimuli. spectra during listening to the $4: 3$ polyrhythms (Figure 5B). Additionally, the 4:3 polyrhythms elicited amplitude peaks at $3 \mathrm{~Hz}$ ( $\mathrm{f}_{2}$ of triple beat) and $4.5 \mathrm{~Hz}$ ( $\mathrm{f}_{3}$ of triple beat) in both musicians and non-musicians. A clear peak at $1.5 \mathrm{~Hz}\left(\mathrm{f}_{1}\right.$ of triple beat) can only be seen in the frequency spectrum of musicians. The frequency spectra during silent periods show a similar pattern: At $1.5 \mathrm{~Hz}$ the amplitude peak of musicians is clearer than the one of non-musicians (Figure 5C). At $3 \mathrm{~Hz}$ a smaller and flatter peak can be found in musicians, but not in non-musicians.

The triple metronome (Figure 5D) with the same rate as the triple beat in the $4: 3$ polyrhythm $(666.67 \mathrm{~ms} / 1.5 \mathrm{~Hz})$ elicited clear peaks at $1.5 \mathrm{~Hz}\left(\mathrm{f}_{1}\right), 3 \mathrm{~Hz}\left(\mathrm{f}_{2}\right), 4.5 \mathrm{~Hz}\left(\mathrm{f}_{3}\right)$, and $6 \mathrm{~Hz}$ $\left(f_{4}\right)$, suggesting that the frequency spectra of $4: 3$ polyrhythms represent a combination of SSEPs found with quadruple rhythms and triple metronome.

For statistical analyses, we computed the mean of normalized spectral peaks at 2 and $4 \mathrm{~Hz}$ to evaluate SSEPs elicited by the quadruple beat and spectral peaks at 1.5 and $3 \mathrm{~Hz}$ to evaluate SSEPs elicited by the triple beat. Figure 6 shows an overview of the SSEP results for the individual frequencies. Ttests against zero revealed that in both musicians and nonmusicians quadruple-beat-related SSEPs were elicited during listening to quadruple rhythms and 4:3 polyrhythms (all $p$ s $<$ 0.001; Table 2). In both groups, triple-beat-related SSEPs were elicited during listening to $4: 3$ polyrhythms and the triplebeat metronome (all $p s \leq 0.001$ ). In silent periods endogenous neural oscillations at triple-beat-related frequencies were found in musicians $(t=2.30, p=0.040)$ but not in non-musicians $(t=$ $1.75, p=0.105)$. Independent samples $t$-tests on the amplitude of quadruple- and triple-beat-related SSEPs during listening to quadruple rhythms, $4: 3$ polyrhythms, and the triple-beat metronome revealed no difference between musicians and nonmusicians (all ps $>0.3$ ). The comparison of endogenous neural
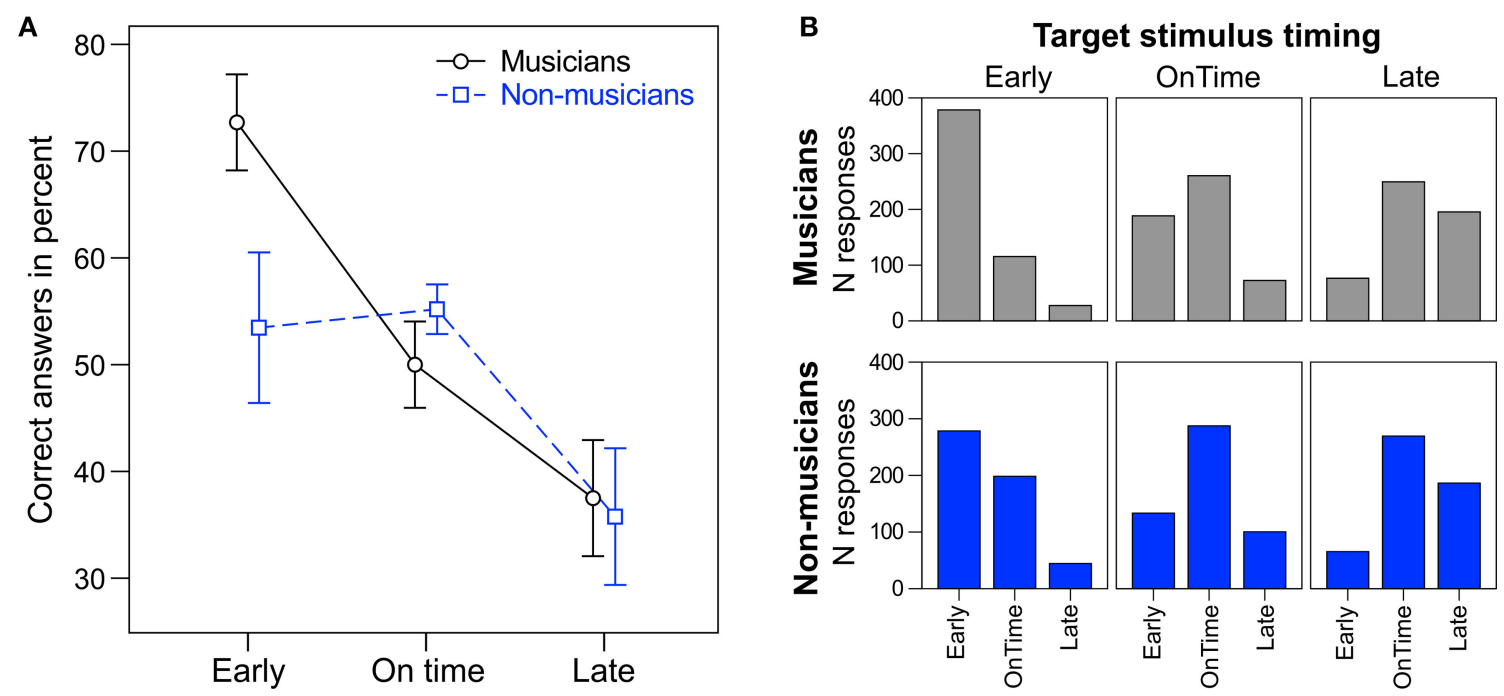

FIGURE 4 | (A) Percentage of correct answers for musicians (round markers, solid black line) and non-musicians (square markers, dashed blue line). Error bars: \pm 1 SE. (B) Total number of responses (early, on time, late) to the different target stimuli (early, on time, late) for musicians (top panel, gray) and non-musicians (bottom panel, blue). 

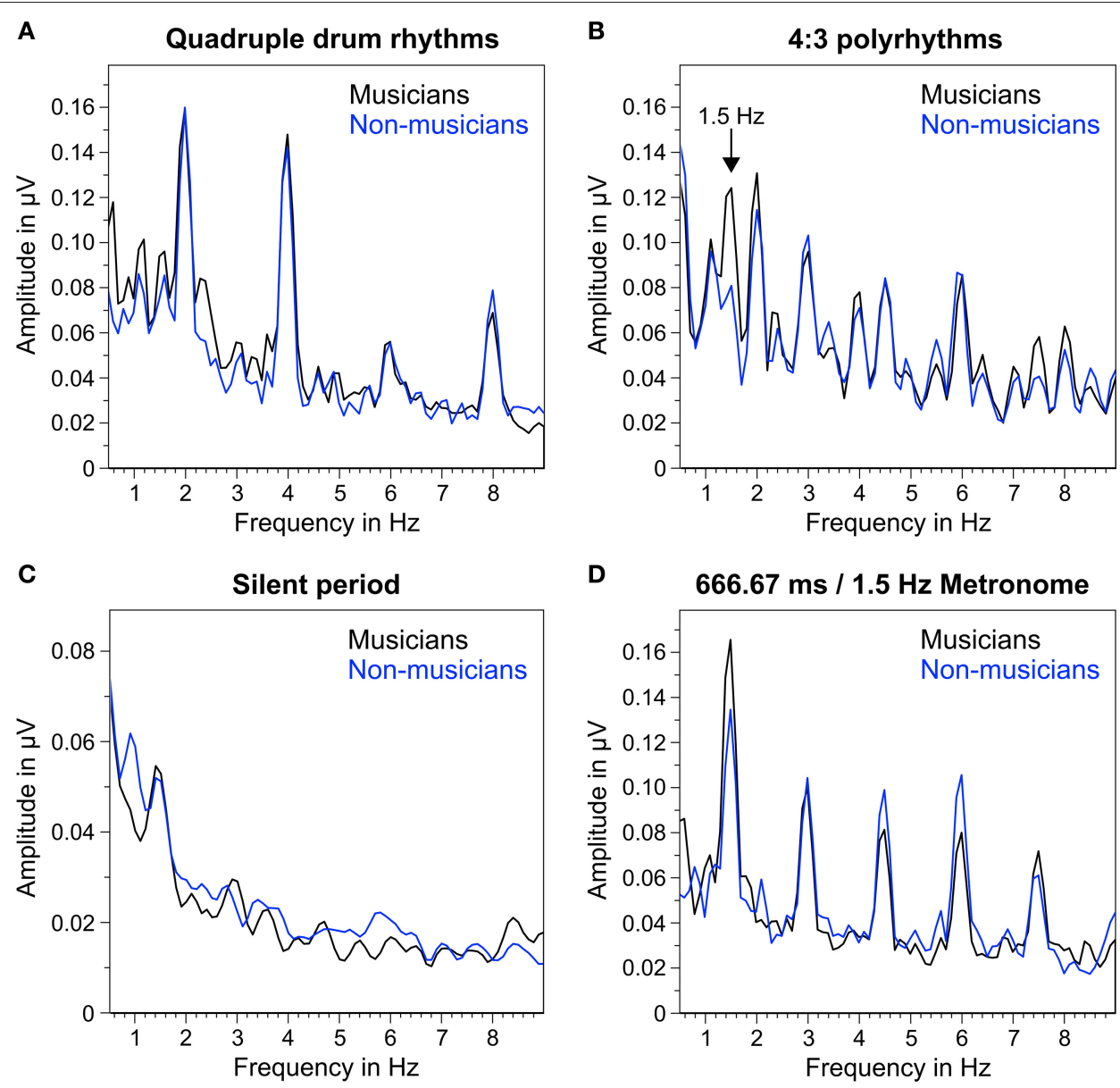

FIGURE 5 | Mean of musicians' (black lines) and non-musicians' (blue lines) frequency spectra of averaged fronto-central electrodes (Fz, FC1, FCz, FC2, Cz). (A) During quadruple drum rhythms (0-4 s of each trial). (B) During 4:3 polyrhythms (4-8 s). (C) During the silent period before target stimulus presentation (8,000-10,333 ms). (D) During 2 min of listening to a metronome with a beat rate of $1.5 \mathrm{~Hz}$ at the beginning and end of the experiment.

oscillations during silent periods showed a difference between musicians' and non-musicians' at the second harmonic $[3 \mathrm{~Hz}$; $\left.t_{(24)}=2.39, p=0.025\right]$, with higher normalized amplitudes for musicians $(M=0.007 \mu \mathrm{V}, S D=0.012)$ than for non-musicians $(M=-0.002 \mu \mathrm{V}, S D=0.007)$. The strength of neural oscillations at the first harmonic frequency $(1.5 \mathrm{~Hz})$ did not differ between the two groups $\left[t_{(24)}=0.33, p=0.746\right]$.

During silent periods, we additionally analyzed beat-related neural oscillations corresponding to correctly and incorrectly judged target stimuli. An ANOVA on normalized peak amplitudes during silent periods with the within-subject factors beat-related frequencies (triple, quadruple) and answer (correct, incorrect) and the between-subject factor musical expertise revealed a main effect of beat-related frequencies $\left[F_{(1,24)}=10.81\right.$, $\left.p=0.003, \eta_{p}{ }^{2}=0.31\right]$ with higher amplitudes at triple-beatrelated frequencies $(1.5$ and $3 \mathrm{~Hz} ; M=0.007 \mu \mathrm{V}, S D=0.016$ ) compared to quadruple-beat-related frequencies $(2$ and $4 \mathrm{~Hz}$; $M=-0.003 \mu \mathrm{V}, S D=0.011$; Figure 7). No other main effect or interaction was found (all $p s>0.18$ ). Two separate ANOVAs, one for each musical expertise group, showed that the main effect of beat-related frequencies was mainly driven by musicians $\left[F_{(1,12)}\right.$ $=7.41, p=0.019, \eta_{p}^{2}=0.22$, for musicians; $F_{(1,12)}=3.44$, $p=0.089, \eta_{p}{ }^{2}=0.31$, for non-musicians; Figure 7]. In both ANOVAs no main effects of answer and no interactions were found (all $p s>0.25$ ).

In silent periods, we found a negative correlation between the amplitude of neural oscillations at triple and quadruple beat frequencies $\left[r_{(26)}=-0.48, p=0.014\right]$, indicating that high amplitudes at triple-beat-related frequencies were associated with low amplitudes at quadruple-beat-related frequencies. During listening to the $4: 3$ polyrhythms, the correlation between the amplitude of neural oscillations at triple and quadruple beat frequencies was not significant $\left[r_{(26)}=-0.07, p=0.752\right]$.

In addition to the analysis of neural oscillations based on discrete FFTs, we computed time-frequency plots based on continuous wavelet transformations. Figure 8 shows two separate time-frequency plots for musicians and non-musicians and the corresponding segments of the auditory stimuli. A comparison between the plots reveals two main differences. (1) In contrast to non-musicians, musicians show ongoing neural 

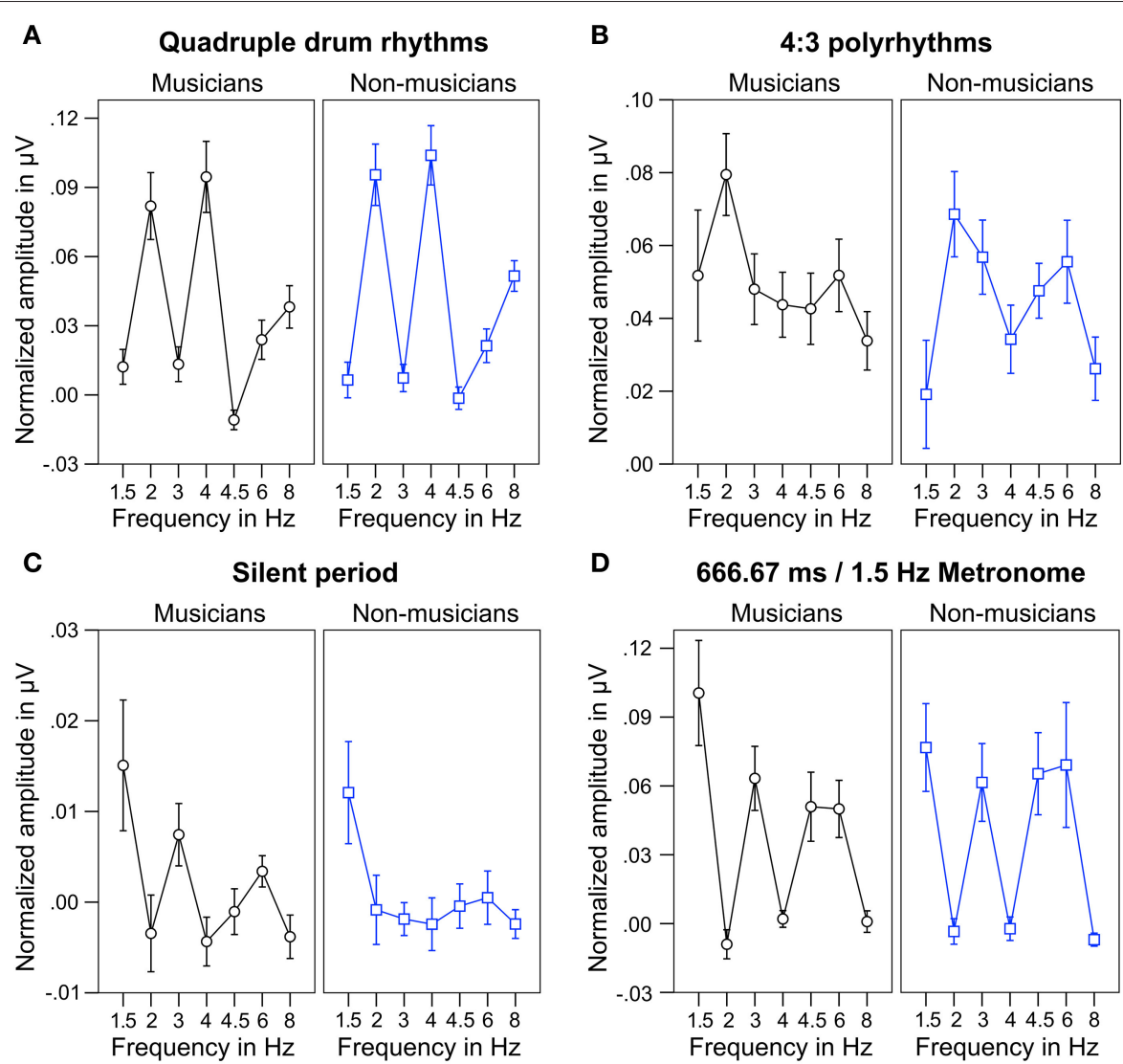

FIGURE 6 | Mean of musicians' (black lines, left panels) and non-musicians' (blue lines, right panels) normalized frequency spectrum amplitudes at quadruple-beat-related $(2,4,6,8 \mathrm{~Hz})$ and triple-beat-related frequencies $(\mathbf{1 . 5}, \mathbf{3}, \mathbf{4 . 5}, 6 \mathrm{~Hz})$. (A) During quadruple drum rhythms (0-4 s of each trial). (B) During 4:3 polyrhythms (4-8 s). (C) During the silent period before target stimulus presentation $(8,000-10,333$ ms). (D) During 2 min of listening to a metronome with a beat rate of $1.5 \mathrm{~Hz}$ at the beginning and end of the experiment. Error bars: $\pm 1 \mathrm{SE}$.

TABLE 2 | Results of $t$-tests against zero on normalized spectral peaks at quadruple-beat-related $(2$ and $4 \mathrm{~Hz})$ and triple-beat-related (1.5 and $3 \mathrm{~Hz})$ frequencies.

\begin{tabular}{|c|c|c|c|c|c|c|}
\hline & & & Quadruple rhythms & 4:3 polyrhythms & Silent breaks & Triple metronome \\
\hline \multirow[t]{4}{*}{ Musicians } & 2 and $4 \mathrm{~Hz}$ normalized peaks & $t_{(12)}$ & 7.28 & 9.94 & -1.80 & -0.76 \\
\hline & & $P$ & $<0.001^{\star \star \star}$ & $<0.001^{\star \star \star}$ & 0.098 & 0.462 \\
\hline & 1.5 and $3 \mathrm{~Hz}$ normalized peaks & $t_{(12)}$ & 2.30 & 5.12 & 2.30 & 4.90 \\
\hline & & $p$ & $0.040^{\star}$ & $<0.001^{\star \star \star}$ & $0.040^{*}$ & $<0.001^{\star \star \star}$ \\
\hline \multirow[t]{4}{*}{ Non-musicians } & 2 and $4 \mathrm{~Hz}$ normalized peaks & $t_{(12)}$ & 9.54 & 5.54 & -1.37 & -0.74 \\
\hline & & $P$ & $<0.001^{\star \star \star}$ & $<0.001^{\star \star \star}$ & 0.195 & 0.473 \\
\hline & 1.5 and $3 \mathrm{~Hz}$ normalized peaks & $t_{(12)}$ & 1.33 & 4.12 & 1.75 & 4.44 \\
\hline & & $p$ & 0.209 & $0.001^{\star \star \star}$ & 0.105 & $0.001^{\star \star \star}$ \\
\hline
\end{tabular}

Significant values $\left({ }^{*} p<0.05,{ }^{* *} p<0.001\right)$ indicate the existence of SSEPS at the corresponding frequencies.

oscillations at $1.5 \mathrm{~Hz}$, starting with the $4: 3$ polyrhythm (see also Figure 9). (2) Compared to non-musicians, musicians have higher amplitudes at 1.5 and $3 \mathrm{~Hz}$ during the silent periods starting at second 8 . In both plots, SSEPs at 2 and $4 \mathrm{~Hz}\left(\mathrm{f}_{1}\right.$ and $\mathrm{f}_{2}$ of quadruple beat) are clearly visible during the quadruple drum rhythms (0-4s) and become weaker during 4:3 polyrhythms (4-8s).

\section{Behavioral Relevance of Endogenous Neural Entrainment}

A positive correlation between triple-beat-related neural oscillations ( 1.5 and $3 \mathrm{~Hz}$ ) during silent periods and the number of correctly classified target stimuli (early, on time, late) indicates that participants with higher endogenous neural entrainment at task-relevant frequencies were better at recognizing the 


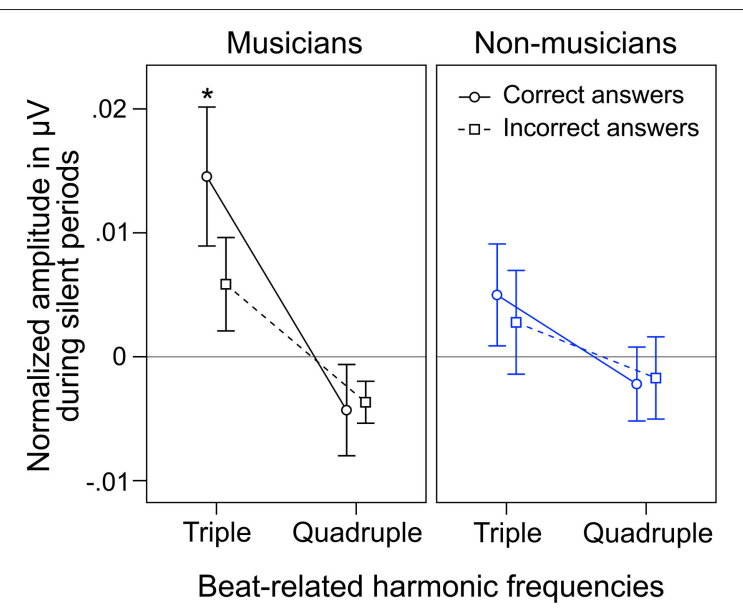

FIGURE 7 | Mean of musicians' (black lines, left panels) and non-musicians' (blue lines, right panels) normalized frequency spectrum amplitudes at quadruple-beat-related ( 2 and $4 \mathrm{~Hz}$ combined) and triple-beat-related frequencies ( 1.5 and $3 \mathrm{~Hz}$ combined) during silent periods before target stimulus presentation. Focusing on the triple beat was more task-relevant than focusing on the quadruple beat. ${ }^{*} p<0.05$ in t-test against zero. Error bars: $\pm 1 \mathrm{SE}$.

timing of the target stimulus $\left[r_{(26)}=0.47, p=0.015\right]$. However, bootstrapping of the correlation ( $k=10,000$ estimations with replacement; sample size $n=26$ ) revealed that this correlation is not stable, as its $95 \%$ CI did include zero. To further evaluate the relationship between behavioral responses and endogenous neural oscillations, we computed two separate correlations for non-musicians $\left[r_{(13)}=0.68, p=0.010\right]$ and musicians $\left[r_{(13)}=\right.$ $0.30, p=0.327$, indicating that the whole-sample correlation was mainly driven by non-musicians (for the significant correlation in non-musicians, bootstrapping $(k=10,000)$ revealed a 95\% CI that did not include zero $[0.38,0.89]$. The correlation between quadruple-beat-related SSEPs $(2$ and $4 \mathrm{~Hz}$ ) and the number of correct answers was negative, but not significant $\left[r_{(26)}=-0.29\right.$, $p=0.147]$.

\section{Event-Related Potentials}

An overview of the ERP results is shown in Table 3. We will first present statistical analyses of ERPs corresponding to correct behavioral responses $\left(\mathrm{ERP}_{\text {cor }}\right.$; Figure 10A) followed by analyses of ERPs corresponding to incorrect behavioral responses

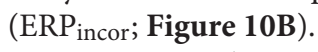

We computed separate ANOVAs on the amplitudes and the locations of $\mathrm{P} 1_{\text {cor }}, \mathrm{N} 1_{\text {cor }}$, and $\mathrm{P} 2_{\text {cor }}$ components with the withinsubject factor target time (early, on time, late) and the betweensubject factor musical expertise. For the amplitudes, a significant main effect of target time was only found for the $\mathrm{P} 1_{\text {cor }}$ component $\left[F_{(2,46)}=7.81, p=0.001, \eta_{p}^{2}=0.25\right.$; Figure 10A $]$. Amplitudes of $\mathrm{P} 1_{\text {cor }}$ evoked by on time targets $(M=0.21 \mu \mathrm{V}, S D=1.99)$ were lower than amplitudes of $\mathrm{P} 1_{\text {cor }}$ evoked by early targets $[M=2.81$, $\left.S D=3.42 ; t_{(24)}=-3.35, p=0.003\right]$ and late targets $[M=3.54$, $\left.S D=3.29 ; t_{(24)}=-4.69, p<0.001\right]$. No difference was found between amplitudes of late and early targets $\left[t_{(24)}=0.67, p>\right.$
0.5]. The effect of musical expertise and the interaction between musical expertise and target time on the $\mathrm{P} 1_{\text {cor }}$ amplitude were not significant $\left(p s>0.4\right.$ ). For the amplitudes of the $\mathrm{N} 1_{\text {cor }}$ and $\mathrm{P} 2_{\text {cor }}$ components, the effects of target time, musical expertise, and the interactions between the two factors were not significant (all $p$ s $>$ 0.2 ). For the locations, a significant main effect of target time was only found for the $\mathrm{P} 2_{\text {cor }}$ component [early: $M=227 \mathrm{~ms}, S D=29$; on time: $M=221 \mathrm{~ms}, S D=31$; late: $M=203 \mathrm{~ms}, S D=21 ; F_{(2,46)}$ $\left.=4.86, p=0.012, \eta_{p}{ }^{2}=0.17\right]$. The effect of musical expertise and the interaction between musical expertise and target time on the $\mathrm{P} 2_{\text {cor }}$ location were not significant $(p s>0.4)$. For the locations of the $\mathrm{N} 1_{\text {cor }}$ and $\mathrm{P} 2_{\text {cor components, the effects of target time, }}$ musical expertise, and the interactions between the two factors were not significant (all $p s>0.08$ ). Separate ANOVAs on the amplitudes of $\mathrm{P} 1_{\text {incor }}, \mathrm{N} 1_{\text {incor }}$, and $\mathrm{P} 2_{\text {incor }}$ components showed no significant main effects of target time or musical expertise, and no interactions (all ps $>0.05$ ).

In an additional analysis we focused on on time targets only and compared the amplitude of ERPs related to correct and incorrect behavioral responses. An ANOVAs on P1 amplitudes revealed a main effect of correct $(M=0.21, S D=1.99)$ vs. incorrect $(M=2.46, S D=2.61)$ on time targets $\left[F_{(1,23)}=\right.$ 17.44, $p<0.001, \eta_{p}{ }^{2}=0.43$; Figure 10C], no significant effect of musical expertise and no significant interaction $(p s>0.2)$. ANOVAs on N1 and P2 amplitudes showed no significant effects of correct vs. incorrect responses, no effects of musical expertise and no interactions ( $p s>0.15)$.

A visual inspection of the time-frequency plots (Figures 8, 9) suggests that in both musicians and non-musicians, the second onset of the triple woodblock (equivalent to the second beat of the triple meter) elicited a prominent event-related potential. A less pronounced event-related potential can be found at the time of the fifth onset of the triple woodblock. An ANOVA on the $\mathrm{N} 1$ amplitude showed that the N1 elicited by the second triple beat $(M=-4.28, S D=2.01)$ was more pronounced than the N1 elicited by the fifth triple beat $\left[M=-1.93, S D=2.09 ; F_{(1,23)}\right.$ $\left.=39.24, p<0.001, \eta_{p}{ }^{2}=0.63\right]$. N1 amplitudes did not differ between musicians and non-musicians and did not interact with musical expertise (both $p s>0.6$ ). Two additional ANOVAs on P1 and P2 amplitudes showed no significant differences between second and fifth beat, musicians and non-musicians, and no interaction (all ps > 0.05). This post-hoc analysis is a first step toward a more systematic characterization of neural entrainment over time.

\section{DISCUSSION}

Empirical findings, computational models, hypotheses and theories suggest that the entrainment of neural oscillations to musical rhythm enables us to disentangle and organize temporal structures and to perceive a steady beat (Large et al., 2015). The current study adds to this growing body of research. By using auditory stimuli that changed from quadruple isorhythms to 3-over-4 polyrhythms, we showed that neural oscillations evolve with changing and overlaying rhythmic frameworks. By adapting a previous design in which the stimuli were interrupted 
A
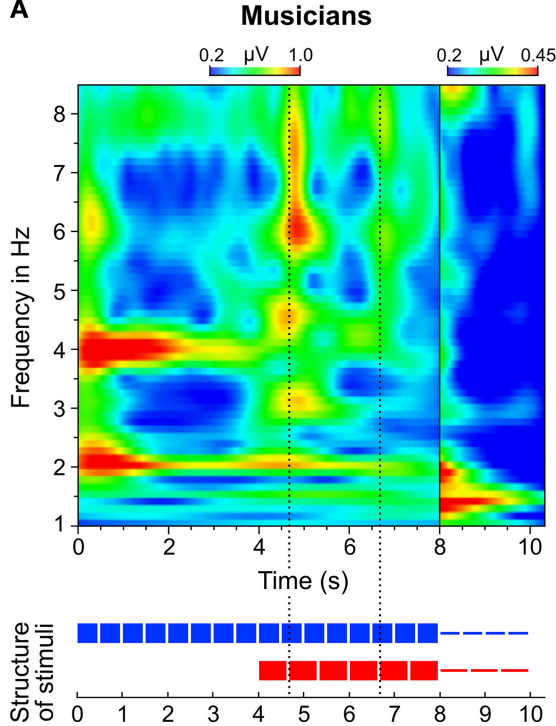

B

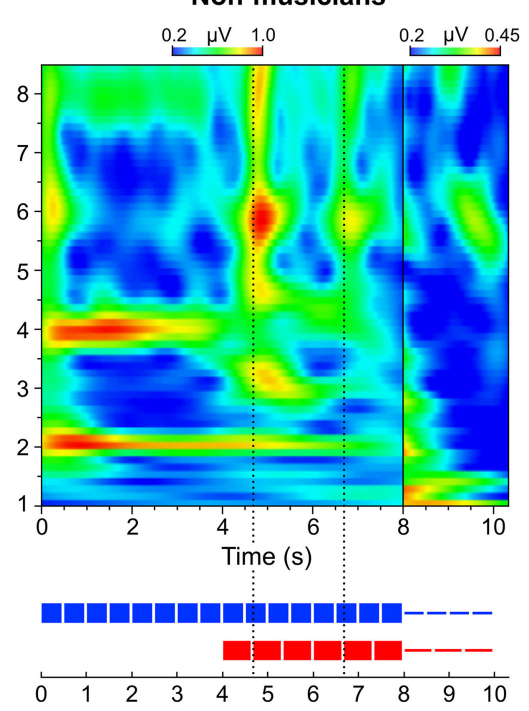

FIGURE 8 | Time-frequency plots of fronto-central electrodes (Fz, FC1, FCz, FC2, Cz) averaged over (A) musicians and (B) non-musicians. Heatmaps represent the mean amplitude over all trials $(0.2-1.0 \mu \mathrm{V}$ during stimulus presentation and $0.2-0.45 \mu \mathrm{V}$ during silent periods).

A

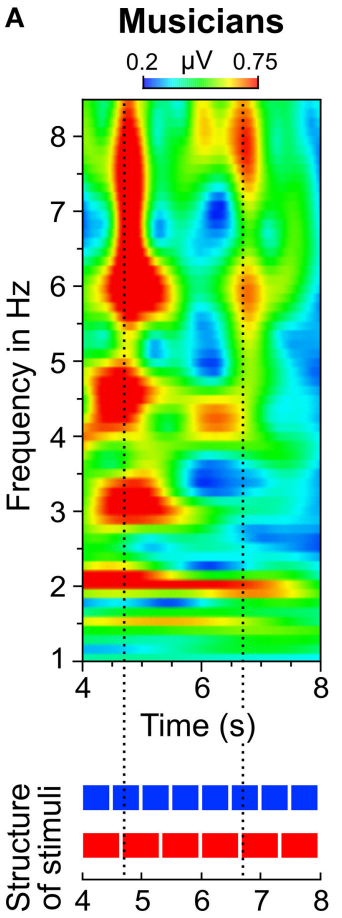

B Non-musicians

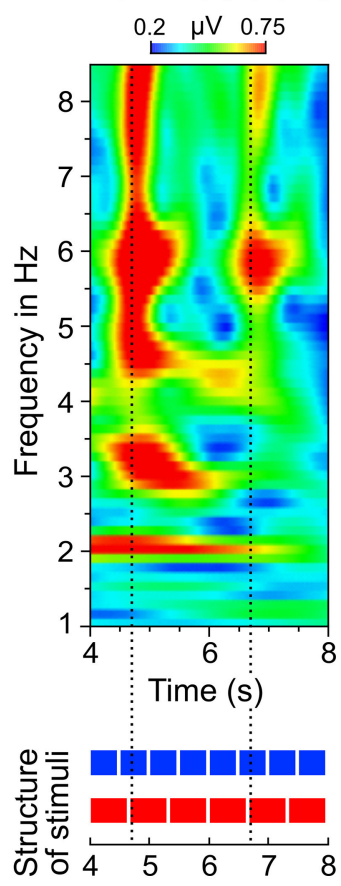

FIGURE 9 | Time-frequency plots of fronto-central electrodes (Fz, FC1, FCz, FC2, Cz) averaged over (A) musicians and (B) non-musicians during listening to the 4:3 polyrhythm. Heatmaps represent the mean amplitude over all trials $(0.2-0.75 \mu \mathrm{V})$.

by silent breaks (Stupacher et al., 2016), we provided evidence that endogenous neural oscillations persist without external stimulation. By combining EEG recordings and behavioral data,

we assessed the relevance of endogenous neural entrainment for rhythm processing. And finally, by comparing data of musicians and non-musicians we gained first insights into whether beatrelated neural oscillations are modulated by musical expertise and in which ways.

The neural resonance theory of pulse and meter proposes that neural oscillations entrain to the temporal patterns of music (Large and Kolen, 1994; Large and Jones, 1999; Large, 2008). Neural entrainment requires a neural oscillator, a periodic external stimulus, and the synchronization between the two (Thut et al., 2011; Large et al., 2015). All of these assumptions were met in the current study. The time-frequency plots in Figures 8, 9 show the evolvement of neural entrainment over time during listening to the different parts of the auditory stimuli. As proposed by the neural resonance theory of pulse and meter (Large and Kolen, 1994; Large and Jones, 1999), the plots show that neural oscillations entrained to the different metric hierarchies of the rhythms. During the isorhythmic quadruple beat (0-4s), neural oscillations of both, musicians and nonmusicians are strongest at 2 and $4 \mathrm{~Hz}$ (quarter-note and eighthnote level of quadruple beat, respectively). During the subsequent 4:3 polyrhythm ( $4-8 \mathrm{~s}$ ) the patterns change: Neural oscillations at 2 and $4 \mathrm{~Hz}$ become weaker and additional oscillations at 1.5 and $3 \mathrm{~Hz}$ emerge. This observation of fine-resolved oscillatory dynamics is supported by more commonly used analyses of the EEG signals' frequency spectra (Table 2, Figures 5, 6), which showed that quadruple rhythms elicited SSEPs at 2 and $4 \mathrm{~Hz}$ and that $4: 3$ polyrhythms additionally elicited neural oscillations at 1.5 and $3 \mathrm{~Hz}$.

Figure 6 shows that the quadruple rhythms (Figure 6A) and the triple-beat metronome (Figure 6D) - the two different parts of the 4:3 polyrhythm-resulted in contrasting SSEP patterns. Each pattern reflects the metric hierarchies of the corresponding 
TABLE 3 | Mean amplitudes in $\mu$ and locations in milliseconds of ERP components (P1, N1, P2) elicited by the target stimuli (early, on time, late) corresponding to correct and incorrect behavioral responses.

\begin{tabular}{|c|c|c|c|c|c|c|c|c|c|c|}
\hline \multirow[t]{2}{*}{ Answer } & \multirow[t]{2}{*}{ Component } & \multirow[t]{2}{*}{ Target time } & \multicolumn{4}{|c|}{ Musicians } & \multicolumn{4}{|c|}{ Non-musicians } \\
\hline & & & $\begin{array}{c}\text { Mean } \\
\text { amplitude }(\mu \mathrm{V})\end{array}$ & $\begin{array}{c}S D \text { of } \\
\text { amplitude }\end{array}$ & $\begin{array}{c}\text { Mean } \\
\text { location (ms) }\end{array}$ & $\begin{array}{c}S D \text { of } \\
\text { location }\end{array}$ & $\begin{array}{c}\text { Mean } \\
\text { amplitude }(\mu \mathrm{V})\end{array}$ & $\begin{array}{c}S D \text { of } \\
\text { amplitude }\end{array}$ & $\begin{array}{c}\text { Mean } \\
\text { location (ms) }\end{array}$ & $\begin{array}{c}S D \text { of } \\
\text { location }\end{array}$ \\
\hline \multirow[t]{9}{*}{ Correct } & P1 & Early & 2.33 & 3.68 & 68 & 17 & 3.26 & 3.24 & 62 & 16 \\
\hline & P1 & On time & 0.71 & 1.90 & 59 & 20 & -0.25 & 2.03 & 63 & 17 \\
\hline & P1 & Late & 3.02 & 3.33 & 64 & 14 & 4.01 & 3.31 & 64 & 17 \\
\hline & N1 & Early & -6.86 & 4.67 & 122 & 17 & -7.73 & 6.42 & 115 & 14 \\
\hline & N1 & On time & -8.99 & 5.15 & 120 & 14 & -7.54 & 3.31 & 117 & 12 \\
\hline & $\mathrm{N} 1$ & Late & -6.49 & 5.44 & 116 & 11 & -6.89 & 4.68 & 120 & 16 \\
\hline & P2 & Early & 12.31 & 5.69 & 225 & 28 & 10.07 & 5.29 & 229 & 30 \\
\hline & P2 & On time & 11.29 & 3.60 & 217 & 24 & 9.42 & 3.49 & 226 & 36 \\
\hline & P2 & Late & 10.84 & 4.65 & 209 & 21 & 9.48 & 4.07 & 199 & 20 \\
\hline \multirow[t]{9}{*}{ Incorrect } & P1 & Early & 1.83 & 2.70 & 64 & 13 & 2.21 & 1.98 & 63 & 17 \\
\hline & P1 & On time & 2.24 & 3.06 & 67 & 10 & 2.67 & 2.23 & 55 & 18 \\
\hline & $\mathrm{P} 1$ & Late & 1.90 & 2.04 & 64 & 16 & 1.22 & 1.60 & 62 & 17 \\
\hline & N1 & Early & -6.33 & 4.10 & 115 & 19 & -6.79 & 5.04 & 119 & 10 \\
\hline & N1 & On time & -6.76 & 3.84 & 117 & 25 & -7.66 & 4.50 & 119 & 18 \\
\hline & N1 & Late & -5.81 & 5.12 & 110 & 21 & -7.30 & 4.33 & 114 & 12 \\
\hline & P2 & Early & 11.89 & 4.38 & 218 & 28 & 8.06 & 3.40 & 224 & 36 \\
\hline & P2 & On time & 10.73 & 3.89 & 233 & 30 & 8.93 & 4.53 & 210 & 29 \\
\hline & P2 & Late & 12.47 & 4.17 & 217 & 29 & 8.82 & 4.82 & 232 & 25 \\
\hline
\end{tabular}

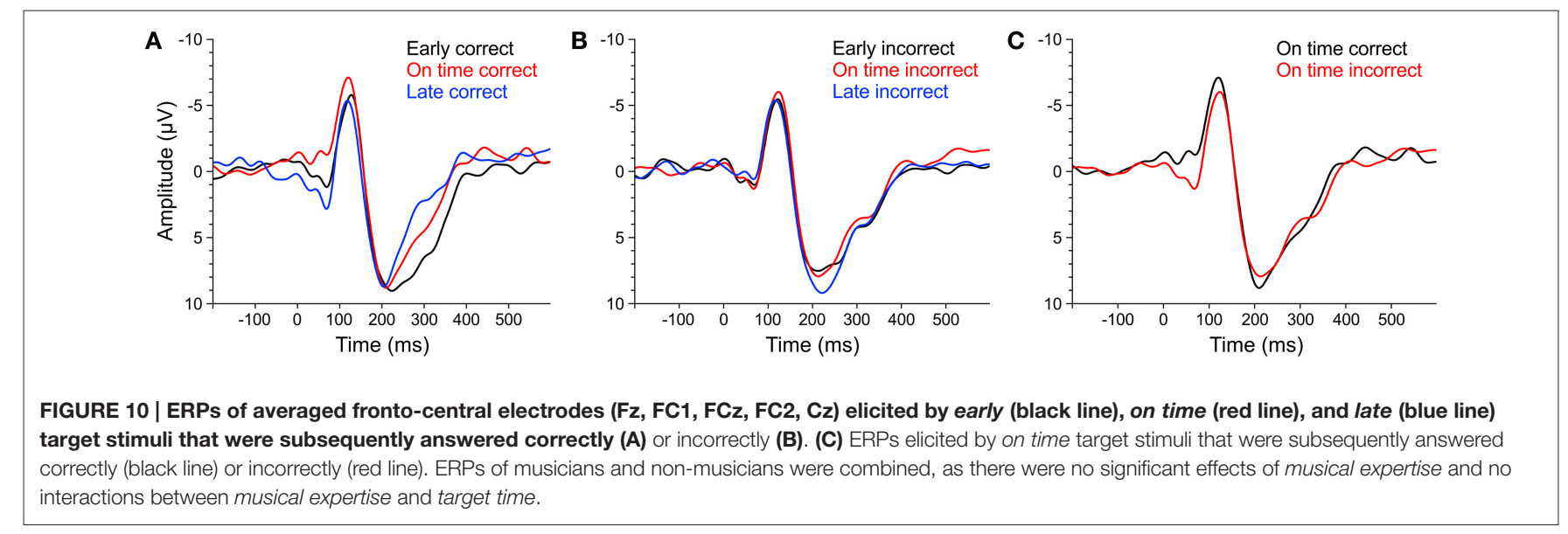

auditory stimulus. SSEPs of the 4:3 polyrhythm (Figure 6B) appear to be a combination of quadruple- and triple-beatrelated SSEPs. This is an interesting finding, because participants were instructed to focus on the triple beat of the polyrhythm. Additionally, the behavioral task made it advantageous for the participants to only track the triple beat. If the two different parts of the polyrhythm could be processed independently by parallel timekeepers, participants should have focused their attention on the triple-beat part. Consequently, with parallel timekeepers the frequency pattern of neural oscillations during the polyrhythm should reflect the triple-beat part and be similar to the frequency patterns during the silent period (Figure 6C) and the triplebeat metronome (Figure 6D). However, in both musicians and non-musicians, the most pronounced SSEP can be found at the quadruple-beat-related frequency of $2 \mathrm{~Hz}$. Additionally, the frequency spectra of both musicians and non-musicians show a prominent peak at $6 \mathrm{~Hz}$-the only frequency shared by the quadruple and triple beat (Figures 5B, 6B). Importantly, the frequency spectra of the sound envelopes of the polyrhythms (Figure 2B, bottom panel) do not show such a prominent peak at $6 \mathrm{~Hz}$. In line with previous findings, these results suggest that polyrhythms, at least up to a certain complexity, are not processed by parallel timekeepers but rather within a shared rhythmic framework (e.g., Deutsch, 1983; Klapp et al., 1985, 1998; Jagacinski et al., 1988; Summers and Kennedy, 1992; Summers et al., 1993; Jones et al., 1995; Peper et al., 1995; Klein and Jones, 
1996; Krampe et al., 2000; Kurtz and Lee, 2003). Further evidence for a shared framework comes from the time frequency plots that revealed a prominent ERP elicited by the second onset of the triple-beat woodblock and a less prominent ERP elicited by the fifth triple-beat onset (marked by dotted lines in Figures 8, 9). The second and fifth onsets of the triple beat woodblock are the first onsets that lie outside the metric grid of the preceding quadruple beat (in the first and second bar of the 4:3 polyrhythm, respectively). Thus, these onsets are less expected than the others, because they violate the previously established metric structure. At first glance this finding seems to contradict the assumption of a shared rhythmic framework. However, as both the amplitudes in the time-frequency plots and the amplitudes of the N1 ERP components indicate that the second onset of the triple beat woodblock elicited more prominent responses than the fifth onset, it can be concluded that the fifth onset was more expected than the second onset. This finding suggests that the triple beat is gradually integrated into the rhythmic framework of the quadruple beat. Consistent with this interpretation, the third and sixth onset of the triple beat woodblock did not elicit an observable ERP.

In general, the finding of evolving neural oscillations that entrain to rhythmic stimuli with changing and overlaying rhythmic frameworks shows that the analysis of SSEPs provides a useful tool for the investigation of polyrhythm processing. Future EEG or EMG experiments could use the frequency-tagging approach to investigate whether more complex polyrhythms are processed differently (e.g., in parallel streams).

Besides neural entrainment to physically present acoustic rhythms, we recorded and analyzed endogenous neural entrainment during the silent periods between the presentations of rhythmic stimuli and target stimuli (Figure 1B). In musicians, the pattern of endogenous neural oscillations (Figure 6C, left panel) resembles the pattern observed during listening to the triple-beat metronome (Figure 6D, left panel). In non-musicians (Figure 6C, right panel), oscillations at $1.5 \mathrm{~Hz}$ stand out. The normalized peak amplitude at $1.5 \mathrm{~Hz}$ for both groups combined was larger than zero $\left[t_{(25)}=3.02, p=0.006\right]$, indicating that endogenous neural oscillations at this frequency persisted throughout silent periods. As expected, these findings suggest that participants successfully imagined that the triple beat continues during silent periods. In line with this conclusion, Figure 7 shows that during the silent periods, task-relevant endogenous neural oscillations at triple-beat-related frequencies $(1.5$ and $3 \mathrm{~Hz})$ were more pronounced than task-irrelevant oscillations at quadruple-beat-related frequencies $(2$ and $4 \mathrm{~Hz}$ ). This is an important finding, as it suggests that neural oscillations during silent periods are not representing a "washing out" effect of the previous stimulation. If the endogenous neural oscillations were based on such a "washing out" effect, amplitudes at triplebeat- and quadruple-beat-related frequencies should be equally high.

The finding of beat-related neural oscillations that persist without external stimulation indicate that neural entrainment to music is not only driven by bottom-up processes, but also by top-down processes and endogenous oscillatory networks. Thus, our results support conclusions of a previous study using the silent break design (Stupacher et al., 2016), and studies showing that beat-related neural oscillations are elicited even if the fundamental beat frequency is not present in the acoustic signal (Nozaradan et al., 2012a, 2016; Large et al., 2015). In contrast to our previous study (Stupacher et al., 2016), which did not show persisting beat-related neural oscillations after participants listened to a drum rhythm, the current study provides direct evidence for endogenously created neural oscillations in a listening task without overt beat-related movement. A plausible reason for this discrepancy is that the instructions lead to different mental imagery states. Part of the task of the current study was to try to imagine that the triple beat continues during the silent period, whereas in Stupacher et al. (2016), participants were not instructed or explicitly motivated to imagine that the beat goes on after the stimulus stopped. By explicitly instructing participants to imagine that the stimulus continues, the current experiment intensified the recruitment of top-down processes, probably leading to strengthened endogenous neural entrainment.

Additional evidence for endogenous neural entrainment comes from the analysis of ERPs elicited by target tones that were presented after the silent periods (Figures 1B,C). For correctly identified target stimuli, the P1 amplitude elicited by targets presented on the triple beat timing grid (on time) was lower than the P1 amplitude elicited by too early and too late targets. We interpret the lower P1 amplitude as reflecting higher prediction accuracy because correctly identified on time targets evoked significantly lower P1 components than incorrectly identified on time targets. Support for this interpretation comes from a study by Moberget et al. (2008) who showed an enhancement of P1 amplitudes elicited by aperiodic stimuli (tones with mixed 650 , 800 , and $950 \mathrm{~ms}$ inter-stimulus-intervals) compared to periodic stimuli (fixed $800 \mathrm{~ms}$ inter-stimulus-interval) in healthy control participants. The functional relevance of the ERP data for timing judgements is supported by the finding that $\mathrm{P} 1$ amplitudes and $\mathrm{P} 2$ latencies were only affected by target time when the subsequent answer in the behavioral task was correct. How musical imagery relates to the ERP findings, why the amplitudes of N1 and P2 components were not modulated by the target time, how the effect of target time on P2 latencies can be explained, and what the underlying mechanisms of the $\mathrm{P} 1$ modulation could be remains a matter of future work.

By including a behavioral task, we were able to assess the functional relevance of endogenous neural entrainment (i.e., beatrelated neural oscillations in silent periods) for rhythm and beat perception. Participants correctly identified the timing of the target stimulus (too early, on time, or too late) in about $51 \%$ of the cases $(33.3 \%$ chance level), indicating that the task was not too easy and not too hard. Musicians tended to give more correct answers than non-musicians. In line with this finding, Rammsayer and Altenmüller (2006) showed that musical training can increase the sensitivity to deviations from regular beats. Interestingly, the difference between musicians and nonmusicians was mainly driven by responses to early target stimuli (Figure 4). Overall, correct identification was highest for early and lowest for late targets. Late targets were often perceived as on time targets (Figure 4B). This results was unexpected, as in 
comparable conditions of a study by Barnes and Jones (2000; e.g., Table 2, $600 \mathrm{~ms}$ standard duration) correct identifications of shorter, same, or longer intervals compared to a context sequence were more symmetrically distributed. When comparing the duration of two time intervals, the preceding context rhythm can affect the temporal judgements (e.g., Barnes and Jones, 2000; McAuley and Jones, 2003). How the context of polyrhythms affects temporal judgements of a subsequent target tone remains to be investigated in greater detail.

For the whole sample of participants, we could show that endogenous neural entrainment improves fine-grained temporal processing, as indicated by a positive correlation between the number of correctly identified target stimuli and the amplitude of neural oscillations at 1.5 and $3 \mathrm{~Hz}$ during silent periods. This finding suggests that listeners use dynamic temporal patterns in form of entrained neural oscillations to process musical rhythms and to predict rhythmic events. In a recent study, Nozaradan et al. (2016), came to similar conclusions by showing that SSEPs during listening to an unsyncopated rhythm positively correlate with synchronization accuracy while tapping in time with the beat of the same rhythm. In the same study the authors computed a measure of endogenous neural entrainment by subtracting the SSEP amplitude during listening to the unsyncopated rhythm from the SSEP amplitude during listening to a syncopated rhythm. Comparable to the directly measured endogenous neural entrainment in the current study, the more indirect measure computed by Nozaradan et al. (2016) was associated with better temporal predictions.

To date, most neuroimaging studies on neural entrainment to music neglected the fact that musical expertise shapes how we perceive the temporal structures of music. In the current study, the comparison between musically trained and untrained participants revealed two main findings.

First, neural entrainment did not differ between musicians and non-musicians during listening to musical rhythms with low (triple metronome), medium (isometric quadruple rhythm), and high (4:3 polyrhythm) rhythmic complexities. These null results are intriguing because various behavioral and neuroimaging studies have shown that musical training sharpens temporal processing (e.g., Drake and Botte, 1993; Rammsayer and Altenmüller, 2006; van Vugt and Tillmann, 2014), improves sensorimotor synchronization accuracy and stability (e.g., Franek et al., 1991; Drake et al., 2000a,b; Krause et al., 2010; Repp, 2010; Baer et al., 2013; Cameron and Grahn, 2014; Baer et al., 2015), deepens the comprehension of metrical structures (e.g., Drake et al., 2000a,b; Brochard et al., 2003; van Zuijen et al., 2005; Geiser et al., 2010), modulates patterns of neural activation during rhythm perception, and strengthens neural auditorymotor coupling (e.g., Haueisen and Knösche, 2001; Bangert and Altenmüller, 2003; Drost et al., 2005; Haslinger et al., 2005; Vuust et al., 2005; D'Ausilio et al., 2006; Bangert et al., 2006; Lahav et al., 2007; Grahn and Rowe, 2009; Stupacher et al., 2013). The question arises as to why neural entrainment during stimulus presentation did not differ between musicians and non-musicians, although all of the aforementioned advantages of musical training seem to be relevant for entrainment processes.
To answer this question we should first take a look at the second main finding from the comparison of musical trained and untrained participants: Endogenous neural entrainment, as measured in silent periods, was stronger in musicians compared to non-musicians. This effect was shown by multiple different analyses. First, the amplitude of endogenous neural oscillations at triple-beat-related frequencies was significantly larger than zero in musicians but not in non-musicians. Second, in musicians, the amplitude of endogenous neural oscillations at triple-beat-related frequencies was significantly larger than the amplitude of taskirrelevant oscillations related to the quadruple beat (Figure 7). In non-musicians, this effect only showed a slight tendency in the same direction. Third, in musicians, the pattern of endogenous neural oscillations during silent periods (left panel of Figure 6C) resembled the pattern of neural oscillations elicited during listening to the triple metronome (left panel of Figure 6D). In contrast, the pattern of non-musicians (right panel of Figure 6C) lacked endogenous neural oscillations at frequencies other than $1.5 \mathrm{~Hz}$. Consistent with this observation, the difference of endogenous neural entrainment between musicians and nonmusicians was mainly driven by the strength of neural oscillations at $3 \mathrm{~Hz}$-the second harmonic of the task-relevant triple beat. Fourth, the time-frequency plots of Figure 8 showed that endogenous neural oscillations $(8-10 \mathrm{~s})$ at triple-beat-related frequencies $(1.5$ and $3 \mathrm{~Hz})$ were more pronounced in musicians compared to non-musicians. And finally, in accordance with the results of the neural entrainment analyses, behavioral results showed that musicians tended to be better at correctly identifying the timing of the target stimulus presented after the silent period.

To sum up the effects of musical expertise, analyses of ongoing neural activity and behavioral results suggest that endogenous neural entrainment during silent periods was stronger in musicians compared to non-musicians. In contrast, no difference of neural entrainment between the two expertise groups was found during stimulus presentation. How can we explain this divergence? The endogenous neural entrainment measured during silent periods is mainly driven by top-down processes, as participants had to imagine the triple beat without any external stimulation. In contrast, the neural entrainment measured during listening to the rhythms reflects a combination of top-down and bottom-up processes (Nozaradan et al., 2016; Stupacher et al., 2016), whereby the bottom-up component is driven by the acoustic input. During listening to music as well as during music production, hard-wired bottom-up sensation and experience-based top-down perception are interdependent. For example, one and the same rhythmic pattern can be interpreted in different ways depending on the metric framework the listener uses to structure the pattern (Honing, 2012). The different interpretations can be a result of different listening experiences, musical training backgrounds, or other individual factors. When briefly exposed to music of a foreign culture (2 weeks), infants, in contrast to adults, developed a culture-specific responsiveness and were able to differentiate culture-specific rhythmic patterns (Hannon and Trehub, 2005). Put another way, long time exposure to culture-specific music can narrow the types of musical patterns that we can effortlessly process. The stronger endogenous neural entrainment in musicians might 
also relate to better musical imagery abilities of musicians or musically engaged individuals compared to less musically trained or engaged individuals (e.g., Aleman et al., 2000; Jakubowski et al., 2016). Although top-down processes are crucial for beat and meter perception, our findings suggest that the amplitude of endogenous neural oscillations is lower than the amplitude of bottom-up driven neural oscillations. Thus, musical expertise might strengthen top-down driven endogenous neural entrainment during rhythm perception, but hard-wired bottomup processes that do not differ between musicians and nonmusicians might cover this effect.

In conclusion, the current study provides new evidence showing that neural oscillations at beat-related frequencies persist after the external acoustic input stopped. This finding indicates that besides bottom-up stimulus-driven processes, neural entrainment to music involves endogenously created neural oscillations related to higher order cognitive processes that enable us to predict what and when sounds are likely to occur. The comparison of musicians and non-musicians suggests that those endogenously created neural oscillations are strengthened by musical expertise. Moreover, our study demonstrates that neural entrainment is crucial for rhythm

\section{REFERENCES}

Aleman, A., Nieuwenstein, M. R., Böcker, K. B., and de Haan, E. H. (2000). Music training and mental imagery ability. Neuropsychologia 38, 1664-1668. doi: 10.1016/S0028-3932(00)00079-8

Arnal, L. H., and Giraud, A.-L. (2012). Cortical oscillations and sensory predictions. Trends Cogn. Sci. 16, 390-398. doi: 10.1016/j.tics.2012.05.003

Baer, L. H., Park, M. T., Bailey, J. A., Chakravarty, M. M., Li, K. Z., and Penhune, V. B. (2015). Regional cerebellar volumes are related to early musical training and finger tapping performance. Neuroimage 109, 130-139. doi: 10.1016/j.neuroimage.2014.12.076

Baer, L. H., Thibodeau, J. N., Gralnick, T. M., Li, K. Z., and Penhune, V. B. (2013). The role of musical training in emergent and event-based timing. Front. Hum. Neurosci. 7:191. doi: 10.3389/fnhum.2013.00191

Bangert, M., and Altenmüller, E. (2003). Mapping perception to action in piano practice: a longitudinal DC-EEG study. BMC Neurosci. 4:26. doi: 10.1186/1471-2202-4-26

Bangert, M., Peschel, T., Schlaug, G., Rotte, M., Drescher, D., Hinrichs, H., et al. (2006). Shared networks for auditory and motor processing in professional pianists: evidence from fMRI conjunction. Neuroimage 30, 917-926. doi: 10.1016/j.neuroimage.2005.10.044

Barnes, R., and Jones, M. R. (2000). Expectancy, attention, and time. Cogn. Psychol. 41, 254-311. doi: 10.1006/cogp.2000.0738

Bendixen, A., SanMiguel, I., and Schröger, E. (2012). Early electrophysiological indicators for predictive processing in audition: a review. Int. J. Psychophysiol. 83, 120-131. doi: 10.1016/j.ijpsycho.2011.08.003

Brochard, R., Abecasis, D., Potter, D., Ragot, R., and Drake, C. (2003). The "ticktock" of our internal clock: direct brain evidence of subjective accents in isochronous sequences. Psychol. Sci. 14, 362-366. doi: 10.1111/1467-9280.24441

Buzsáki, G., and Draguhn, A. (2004). Neuronal oscillations in cortical networks. Science 304, 1926-1929. doi: 10.1126/science.1099745

Cameron, D. J., and Grahn, J. A. (2014). Enhanced timing abilities in percussionists generalize to rhythms without a musical beat. Front. Hum. Neurosci. 8:1003. doi: 10.3389/fnhum.2014.01003

Chen, J. L., Penhune, V. B., and Zatorre, R. J. (2008). Moving on time: brain network for auditory-motor synchronization is modulated by perception and processing, even when listening to stimuli with complex rhythmic frameworks such as polyrhythms.

\section{AUTHOR CONTRIBUTIONS}

JS and MW designed the study, managed data collection, analyzed the data, and wrote the manuscript. GW designed the study and wrote the manuscript.

\section{ACKNOWLEDGMENTS}

JS was supported by a DOC fellowship of the Austrian Academy of Sciences at the Department of Psychology, University of Graz. We thank Aleksandra Krajnc and Vanessa Hinterleitner for assistance in data collection. The authors acknowledge the financial support by the University of Graz.

\section{SUPPLEMENTARY MATERIAL}

The Supplementary Material for this article can be found online at: http://journal.frontiersin.org/article/10.3389/fnins. 2017.00208/full\#supplementary-material rhythm complexity and musical training. J. Cogn. Neurosci. 20, 226-239. doi: 10.1162/jocn.2008.20018

D'Ausilio, A., Altenmüller, E., Olivetti Belardinelli, M., and Lotze, M. (2006). Cross-modal plasticity of the motor cortex while listening to a rehearsed musical piece. Eur. J. Neurosci. 24, 955-958. doi: $10.1111 /$ j.1460-9568.2006.04960.x

Deutsch, D. (1983). The generation of two isochronous sequences in parallel. Percept. Psychophys. 34, 331-337. doi: 10.3758/BF03203045

Drake, C., and Botte, M.-C. (1993). Tempo sensitivity in auditory sequences: evidence for a multiple-look model. Percept. Psychophys. 54, 277-286. doi: 10.3758/BF03205262

Drake, C., Jones, M. R., and Baruch, C. (2000a). The development of rhythmic attending in auditory sequences: attunement, referent period, focal attending. Cognition 77, 251-288. doi: 10.1016/S0010-0277(00)00106-2

Drake, C., Penel, A., and Bigand, E. (2000b). Tapping in time with mechanically and expressively performed music. Music Percept. 18, 1-23. doi: $10.2307 / 40285899$

Drost, U. C., Rieger, M., Brass, M., Gunter, T. C., and Prinz, W. (2005). When hearing turns into playing: movement induction by auditory stimuli in pianists. Q. J. Exp. Psychol. A 58, 1376-1389. doi: 10.1080/02724980443000610

Fidali, B. C., Poudrier, E., and Repp, B. H. (2013). Detecting perturbations in polyrhythms: effects of complexity and attentional strategies. Psychol. Res. 77, 183-195. doi: 10.1007/s00426-011-0406-8

Franek, M., Mates, J., Radil, T., Beck, K., and Pöppel, E. (1991). Finger tapping in musicians and nonmusicians. Int. J. Psychophysiol. 11, 277-279. doi: 10.1016/0167-8760(91)90022-P

Frey, J. N., Ruhnau, P., and Weisz, N. (2015). Not so different after all: the same oscillatory processes support different types of attention. Brain Res. 1626, 183-197. doi: 10.1016/j.brainres.2015.02.017

Fries, P. (2005). A mechanism for cognitive dynamics: neuronal communication through neuronal coherence. Trends Cogn. Sci. 9, 474-480. doi: 10.1016/j.tics.2005.08.011

Geiser, E., Sandmann, P., Jäncke, L., and Meyer, M. (2010). Refinement of metre perception - training increases hierarchical metre processing. Eur. J. Neurosci. 32, 1979-1985. doi: 10.1111/j.1460-9568.2010.07462.x

Gordon, E. E. (1985). Research studies in audiation: I. Bull. Council Res. Music Educ. 84, 34-50. 
Gordon, E. E. (1999). All about audiation and music aptitudes. Music Educ. J. 86, 41-44. doi: $10.2307 / 3399589$

Grahn, J. A., and Rowe, J. B. (2009). Feeling the beat: premotor and striatal interactions in musicians and nonmusicians during beat perception. J. Neurosci. 29, 7540-7548. doi: 10.1523/JNEUROSCI.2018-08.2009

Gratton, G., Coles, M. G., and Donchin, E. (1983). A new method for off-line removal of ocular artifact. Electroencephalogr. Clin. Neurophysiol. 55, 468-484. doi: 10.1016/0013-4694(83)90135-9

Hannon, E. E., and Trehub, S. E. (2005). Metrical categories in infancy and adulthood. Psychol. Sci. 16, 48-55. doi: 10.1111/j.0956-7976.2005.00779.x

Haslinger, B., Erhard, P., Altenmüller, E., Schroeder, U., Boecker, H., and Ceballos-Baumann, A. O. (2005). Transmodal sensorimotor networks during action observation in professional pianists. J. Cogn. Neurosci. 17, 282-293. doi: 10.1162/0898929053124893

Haueisen, J., and Knösche, T. R. (2001). Involuntary motor activity in pianists evoked by music perception. J. Cogn. Neurosci. 13, 786-792. doi: 10.1162/08989290152541449

Honing, H. (2012). Without it no music: beat induction as a fundamental musical trait. Ann. N.Y. Acad. Sci. 1252, 85-91. doi: 10.1111/j.1749-6632.2011.06402.x

Iyer, V. (2002). Embodied mind, situated cognition, and expressive microtiming in African-American music. Music Percept. 19, 387-414. doi: $10.1525 / \mathrm{mp} .2002 .19 .3 .387$

Jagacinski, R. J., Marshburn, E., Klapp, S. T., and Jones, M. R. (1988). Tests of parallel versus integrated structure in polyrhythmic tapping. J. Mot. Behav. 20, 416-442. doi: 10.1080/00222895.1988.10735455

Jakubowski, K., Farrugia, N., and Stewart, L. (2016). Probing imagined tempo for music: effects of motor engagement and musical experience. Psychol. Music 44, 1274-1288. doi: 10.1177/0305735615625791

Jones, M. R., Jagacinski, R. J., Yee, W., Floyd, R. L., and Klapp, S. T. (1995). Tests of attentional flexibility in listening to polyrhythmic patterns. J. Exp. Psychol. 21, 293-307. doi: 10.1037/0096-1523.21.2.293

Keller, P. E., and Burnham, D. K. (2005). Musical meter in attention to multipart rhythm. Music Percept. 22, 629-661. doi: 10.1525/mp.2005.22.4.629

Klapp, S. T. (1979). Doing two things at once: the role of temporal compatibility. Mem. Cogn. 7, 375-381. doi: 10.3758/BF03196942

Klapp, S. T., Hill, M. D., Tyler, J. G., Martin, Z. E., Jagacinski, R. J., and Jones, M. R. (1985). On marching to two different drummers: perceptual aspects of the difficulties. J. Exp. Psychol. 11, 814-827. doi: 10.1037/0096-1523.11.6.814

Klapp, S. T., Nelson, J. M., and Jagacinski, R. J. (1998). Can people tap concurrent bimanual rhythms independently? J. Mot. Behav. 30, 301-322.

Klein, J. M., and Jones, M. R. (1996). Effects of attentional set and rhythmic complexity on attending. Percept. Psychophys. 58, 34-46. doi: 10.3758/BF03205473

Krampe, R. T., Kliegl, R., Mayr, U., Engbert, R., and Vorberg, D. (2000). The fast and the slow of skilled bimanual rhythm production: parallel versus integrated timing. J. Exp. Psychol. 26, 206-233. doi: 10.1037/0096-1523.26.1.206

Krause, V., Pollok, B., and Schnitzler, A. (2010). Perception in action: the impact of sensory information on sensorimotor synchronization in musicians and non-musicians. Acta Psychol. 133, 28-37. doi: 10.1016/j.actpsy.2009. 08.003

Kurtz, S., and Lee, T. D. (2003). Part and whole perceptual-motor practice of a polyrhythm. Neurosci. Lett. 338, 205-208. doi: 10.1016/S0304-3940(02)01394-0

Lahav, A., Saltzman, E., and Schlaug, G. (2007). Action representation of sound: audiomotor recognition network while listening to newly acquired actions. J. Neurosci. 27, 308-314. doi: 10.1523/JNEUROSCI.4822-06.2007

Lange, K. (2009). Brain correlates of early auditory processing are attenuated by expectations for time and pitch. Brain Cogn. 69, 127-137. doi: 10.1016/j.bandc.2008.06.004

Large, E. W. (2008). "Resonating to musical rhythm: theory and experiment," in Psychology of Time, ed S. Grondin (Bingley: Emerald), 189-231.

Large, E. W., Herrera, J. A., and Velasco, M. J. (2015). Neural networks for beat perception in musical rhythm. Front. Syst. Neurosci. 9:159. doi: 10.3389/fnsys.2015.00159

Large, E. W., and Jones, M. R. (1999). The dynamics of attending: how people track time-varying events. Psychol. Rev. 106, 119-159. doi: 10.1037/0033-295X.106.1.119

Large, E. W., and Kolen, J. F. (1994). Resonance and the perception of musical meter. Conn. Sci. 6, 177-208. doi: 10.1080/09540099408915723
Lartillot, O., and Toiviainen, P. (2007). “A matlab toolbox for musical feature extraction from audio," in Proceedings of the 10th Int. Conference on Digital Audio Effects (DAFx-07). (Bordeaux).

Locke, D. (1982). Principles of offbeat timing and cross-rhythm in southern Eve dance drumming. Ethnomusicology 26, 217-246. doi: 10.2307/851524

London, J. (2004). Hearing in Time: Psychological Aspects of Musical Meter. New York, NY: Oxford University Press.

MacDougall, H. G., and Moore, S. T. (2005). Marching to the beat of the same drummer: the spontaneous tempo of human locomotion. J. Appl. Physiol. 99, 1164-1173. doi: 10.1152/japplphysiol.00138.2005

Matthews, T. E., Thibodeau, J. N., Gunther, B. P., and Penhune, V. B. (2016). The impact of instrument-specific musical training on rhythm perception and production. Front. Psychol. 7:69. doi: 10.3389/fpsyg.2016.00069

McAuley, J. D., and Jones, M. R. (2003). Modeling effects of rhythmic context on perceived duration: a comparison of interval and entrainment approaches to short-interval timing. J. Exp. Psychol. 29, 1102-1125. doi: 10.1037/0096-1523.29.6.1102

Moberget, T., Karns, C. M., Deouell, L. Y., Lindgren, M., Knight, R. T., and Ivry, R. B. (2008). Detecting violations of sensory expectancies following cerebellar degeneration: a mismatch negativity study. Neuropsychologia 46, 2569-2579. doi: 10.1016/j.neuropsychologia.2008.03.016

Moelants, D., and van Noorden, L. (2005). The influence of pitch interval on the perception of polyrhythms. Music Percept. 22, 425-440. doi: $10.1525 / \mathrm{mp} .2005 .22 .3 .425$

Nozaradan, S. (2014). Exploring how musical rhythm entrains brain activity with electroencephalogram frequency-tagging. Philos. Trans. R. Soc. B 369:20130393. doi: 10.1098/rstb.2013.0393

Nozaradan, S., Peretz, I., and Keller, P. E. (2016). Individual differences in rhythmic cortical entrainment correlate with predictive behavior in sensorimotor synchronization. Sci. Rep. 6:20612. doi: 10.1038/srep20612

Nozaradan, S., Peretz, I., Missal, M., and Mouraux, A. (2011). Tagging the neuronal entrainment to beat and meter. J. Neurosci. 31, 10234-10240. doi: 10.1523/JNEUROSCI.0411-11.2011

Nozaradan, S., Peretz, I., and Mouraux, A. (2012a). Selective neuronal entrainment to the beat and meter embedded in a musical rhythm. J. Neurosci. 32, 17572-17581. doi: 10.1523/JNEUROSCI.3203-12.2012

Nozaradan, S., Peretz, I., and Mouraux, A. (2012b). Steady-state evoked potentials as an index of multisensory temporal binding. Neuroimage 60, 21-28. doi: 10.1016/j.neuroimage.2011.11.065

Nozaradan, S., Zerouali, Y., Peretz, I., and Mouraux, A. (2015). Capturing with EEG the neural entrainment and coupling underlying sensorimotor synchronization to the beat. Cereb. Cortex 25, 736-747. doi: 10.1093/cercor/bht261

Osborn, B. (2010). Beats that commute: algebraic and kinesthetic models for math-rock grooves. Gamut 3, 43-68.

Peper, C. L. E., Beek, P. J., and Van Wieringen, P. C. W. (1995). Coupling strength in tapping a 2:3 polyrhythm. Hum. Mov. Sci. 14, 217-245. doi: 10.1016/0167-9457(95)00010-P

Pieslak, J. (2007). Re-casting metal: rhythm and meter in the music of Meshuggah. Music Theor. Spectr. 29, 219-246. doi: 10.1525/mts.2007.29.2.219

Poudrier, E., and Repp, B. H. (2013). Can musicians track two different beats simultaneously? Music Percept. 30, 369-390. doi: 10.1525/mp.2013.30.4.369

Pressing, J. (2002). Black Atlantic rhythm: its computational and transcultural foundations. Music Percept. 19, 285-310. doi: 10.1525/mp.2002.19.3.285

Rammsayer, T., and Altenmüller, E. (2006). Temporal information processing in musicians and nonmusicians. Music Percept. 24, 37-48. doi: $10.1525 / \mathrm{mp} .2006 .24 .1 .37$

Repp, B. H. (2005). Sensorimotor synchronization: a review of the tapping literature. Psychon. Bull. Rev. 12, 969-992. doi: 10.3758/BF03206433

Repp, B. H. (2010). Sensorimotor synchronization and perception of timing: effects of music training and task experience. Hum. Mov. Sci. 29, 200-213. doi: 10.1016/j.humov.2009.08.002

Salimpoor, V. N., Zald, D. H., Zatorre, R. J., Dagher, A., and McIntosh, A. R. (2015). Predictions and the brain: how musical sounds become rewarding. Trends Cogn. Sci. 19, 86-91. doi: 10.1016/j.tics.2014.12.001

Sanabria, D., and Correa, Á. (2013). Electrophysiological evidence of temporal preparation driven by rhythms in audition. Biol. Psychol. 92, 98-105. doi: $10.1016 /$ j.biopsycho.2012.11.012 
Schroeder, C. E., and Lakatos, P. (2009). Low-frequency neuronal oscillations as instruments of sensory selection. Trends Neurosci. 32, 1-16. doi: 10.1016/j.tins.2008.09.012

Singer, W. (1999). Neurobiology: striving for coherence. Nature 397, 391-393. doi: $10.1038 / 17021$

Stupacher, J., Hove, M. J., Novembre, G., Schütz-Bosbach, S., and Keller, P. E. (2013). Musical groove modulates motor cortex excitability: a TMS investigation. Brain Cogn. 82, 127-136. doi: 10.1016/j.bandc.2013. 03.003

Stupacher, J., Witte, M., Hove, M. J., and Wood, G. (2016). Neural entrainment in drum rhythms with silent breaks: evidence from steady-state evoked and eventrelated potentials. J. Cogn. Neurosci. 28, 1865-1877. doi: 10.1162/jocn_a_01013

Summers, J. J., and Kennedy, T. M. (1992). Strategies in the production of a 5:3 polyrhythm. Hum. Mov. Sci. 11, 101-112. doi: 10.1016/0167-9457(92) 90053-E

Summers, J. J., Todd, J. A., and Kim, Y. H. (1993). The influence of perceptual and motor factors on bimanual coordination in a polyrhythmic tapping task. Psychol. Res. 55, 107-115. doi: 10.1007/BF00419641

Thut, G., Schyns, P. G., and Gross, J. (2011). Entrainment of perceptually relevant brain oscillations by non-invasive rhythmic stimulation of the human brain. Front. Psychol. 2:170. doi: 10.3389/fpsyg.2011.00170

Tierney, A., and Kraus, N. (2015). Neural entrainment to the rhythmic structure of music. J. Cogn. Neurosci. 27, 400-408. doi: 10.1162/jocn_a_00704

van Noorden, L., and Moelants, D. (1999). Resonance in the perception of musical pulse. J. New Music Res. 28, 43-66. doi: 10.1076/jnmr.28.1.4 3.3122

van Vugt, F. T., and Tillmann, B. (2014). Thresholds of auditory-motor coupling measured with a simple task in musicians and non-musicians:
Was the sound simultaneous to the key press? PLoS ONE 9:e87186. doi: 10.1371/journal.pone.0087176

van Zuijen, T. L., Sussman, E., Winkler, I., Näätänen, R., and Tervaniemi, M. (2005). Auditory organization of sound sequences by a temporal or numerical regularity - A mismatch negativity study comparing musicians and non-musicians. Cogn. Brain Res. 23, 270-276. doi: 10.1016/ j.cogbrainres.2004.10.007

Vuust, P., Pallesen, K. J., Bailey, C., van Zuijen, T. L., Gjedde, A., Roepstorff, A., and Østergaard, L. (2005). To musicians, the message is in the meter: pre-attentive neuronal responses to incongruent rhythm are left-lateralized in musicians. Neuroimage 24, 560-564. doi: 10.1016/j.neuroimage.2004.08.039

Wöllner, C., and Halpern, A. R. (2016). Attentional flexibility and memory capacity in conductors and pianists. Attent. Percept. Psychophys. 78, 198-208. doi: 10.3758/s13414-015-0989-Z

Zatorre, R. J., and Halpern, A. R. (2005). Mental concerts: musical imagery and auditory cortex. Neuron 47, 9-12. doi: 10.1016/j.neuron.2005.06.013

Conflict of Interest Statement: The authors declare that the research was conducted in the absence of any commercial or financial relationships that could be construed as a potential conflict of interest.

Copyright (c) 2017 Stupacher, Wood and Witte. This is an open-access article distributed under the terms of the Creative Commons Attribution License (CC BY). The use, distribution or reproduction in other forums is permitted, provided the original author(s) or licensor are credited and that the original publication in this journal is cited, in accordance with accepted academic practice. No use, distribution or reproduction is permitted which does not comply with these terms. 